\title{
Hot compression behaviour and microstructural evolution in aluminium based composites: an assessment of the role of reinforcements and deformation parameters
}

Saheed Adeoye Babalola ${ }^{1, *}$, Kenneth Kanayo Alaneme ${ }^{1,2}$, Samuel Ranti Oke ${ }^{1,2}$, Lesley Heath Chown ${ }^{3}$, Nthabiseng Beauty Maledi ${ }^{3}$, and Michael Oluwatosin Bodunrin ${ }^{1,3,4}$

1 Materials Design and Structural Integrity Research Group, Department of Metallurgical and Materials Engineering, Federal University of Technology Akure, P.M.B. 704, Ondo State, Nigeria

${ }^{2}$ Centre for Nanoengineering and Tribocorrosion, School of Mining, Metallurgy and Chemical Engineering, University of Johannesburg, South Africa

3 School of Chemical and Metallurgical Engineering, DST-NRF Centre of Excellence in Strong Materials and African Materials Science and Engineering Network (AMSEN): all University of the Witwatersrand, Private Bag 3, WITS, 2050, Johannesburg, South Africa

4 African Academy of Sciences, P.O. Box 24916-00502 Nairobi, Kenya

Received: 25 July 2020 / Accepted: 31 January 2021

\begin{abstract}
The response of two different types of aluminium matrix composites (AMCs) reinforced with silicon carbide ceramic particulates or nickel metallic particulates to hot compression testing parameters was evaluated. The composites were produced via two-step stir-casting technique. Axisymmetric compression testing was performed on the samples at different deformation temperatures of 220 and $370{ }^{\circ} \mathrm{C}, 0.5$ and $5 \mathrm{~s}^{-1}$ strain rates and total strains of 0.6 and 1.2. The initial and post-deformed microstructures were studied using optical and scanning electron microscopy. The results show that flow stress was significantly influenced by imposed deformation parameters and the type of reinforcements used in the AMCs. Nickel particulate reinforced aluminium matrix composite (AMC) showed superior resistance to deformation in comparison with silicon carbide reinforced AMC under the different testing conditions. In both AMCs, work hardening, dynamic recovery and dynamic recrystallisation influenced their response to imposed parameters. The signature of dynamic recrystallisation was very apparent in aluminium matrix composite reinforced with nickel particulates.
\end{abstract}

Keywords: Metallic reinforcements / compressive strength / deformation / microstructure / hot working / aluminium matrix composite / aluminium / nickel / silicon carbide

\section{Introduction}

Over the last two decades, aluminium matrix composites have not only taken the lead among other metal matrix composites within various domains of applications but have also replaced a number of traditional alloys in different applications particularly in the automotive industries $[1,2]$. The use of aluminium composites in the production of pistons, connecting rods, brake disc and other notable automotive parts in commercial quantities has been attributed to the ease of producing the composites using conventional processing techniques such as casting and powder metallurgy (PM) [3,4]. These production

\footnotetext{
* e-mail: babalolasaheed89@gmail.com
}

routes are the most utilised routes for developing monolithic metallic materials [3-5]. Additionally, AMCs uniqueness in exhibiting various property combinations that are difficult to obtain in monolithic metallic alloys has made this class of material even more popular [6]. Despite these attributes, the major drawbacks of AMCs are inferior toughness, poor ductility, poor formability and low damping capacity in comparison with some monolithic alloys [7-9]. In typical metallic systems, thermomechanical treatments are used in improving hardness and strength but ductility and toughness are often compromised, hence researchers and manufacturers often find optimum processing conditions for obtaining good combination of strength and ductility $[10,11]$. In AMCs, similar approach has been used such that addition of ceramic particulates and thermomechanical treatment resulted in significant 
improvement in strength levels but with compromised ductility and toughness $[12,13]$. A good number of studies have established optimum conditions for obtaining a fairly balanced mechanical properties in AMCs [14,15].

The challenges of poor ductility, toughness and formability in AMCs are attributable to poor wettability of the reinforcements by the molten metal matrix in the case of cast AMCs [16]. Additionally, segregation or agglomeration of reinforcing materials [17], reinforcement induced voids and cracks, particle debonding and cracking also lead to poor ductility and formability in both cast and powder metallurgy AMCs [17,18]. In resolving these challenges in AMCs, researchers have explored the possibility of manipulating reinforcement size, shapes and types $[19,20]$. Some other researchers investigated the use of nanosized reinforcing particulates to achieve significant strength improvement while retaining ductility [21], other researchers considered extending the idea of using hybrid reinforcements to tackle the problem of inferior ductility in AMCs [22,23]. The combination of micro and nanosized reinforcements were attempted by some research groups [24,25] while others explored combination of different nanosized reinforcements when addressing the challenge of ductility improvement in AMCs [26,27]. It is worthy of note that all these approaches recorded some appreciable level of success, but traditional alloys still have superior ductility, toughness and formability in comparison with developed composites. Therefore, it becomes difficult to transfer the marginal improvement in ductility of AMCs to existing applications where the ductility of monolithic alloys is considered as gold standard. Research efforts seeking to improve ductility and formability in AMCs will continue to be of interest to materials scientists and engineers.

In 2015, Bodunrin et al. [28] provided an overview of the different reinforcement philosophies that were adopted by researchers in improving properties of AMCs as well as minimising cost of production. In their review paper, the use of metallic reinforcement in AMCs was not covered as this idea was probably at the conceptualisation phase. However, in 2019, Alaneme et al. [29] presented a succinct review on the applicability of metallic particulates as alternative reinforcing material to conventional ceramic materials and agro-waste derivatives as reinforcements in AMCs. It is evident from this review that the idea of using metallic and metallic glasses as reinforcements in AMCs is attracting several research interests especially with the sudden increase in the number of published articles in this area. Common metallic reinforcements such as particulates of iron, nickel, machined steel chips among others have reportedly improved ductility levels in this new class of AMCs and this trend was attributed to the inherent ductile nature of those metallic particles and the improved wettability between the metallic reinforcements and the metal matrices [29-32].

However, to the best of the authors' knowledge there is currently no published article on the mechanical behaviour of this class of AMCs at high temperatures. Some automotive parts such as brake drums, brake discs, engine sump are subjected to stresses at high temperatures which may have adverse effect on mechanical properties. The response of metallic reinforced aluminium composites to different strain rates and deformation temperatures will provide insights into their integrity under high temperature conditions. These insights will be useful in ranking the composites as suitable material for application where damping capacity and high temperature strength are crucial.

Unlike in other studies where the performance of ceramic reinforced aluminium composites under various hot working conditions were investigated extensively, studies covering the hot deformation behaviour of metallic reinforced AMCs are rarely available. Consequently, as a first step in understanding high temperature behaviour of metallic particulate reinforced AMC, this work provides information on the response of nickel reinforced AMC to typical hot working parameters such as strain rates and deformation temperatures. The response of this composite is compared with AMC reinforced with conventional silicon carbide particulates.

\section{Experimental procedure}

The samples used in this study were obtained from twostep stir-cast aluminium-based composites reinforced with $6 \mathrm{wt} \%$ silicon carbide $(\sim 50 \mu \mathrm{m})$ or $6 \mathrm{wt} \%$ nickel particulates $(\sim 10 \mu \mathrm{m})$. The composition of the aluminium (6063) which was the matrix material is $0.4 \mathrm{wt} \% \mathrm{Si}-0.47 \mathrm{wt} \% \mathrm{Mg}-$ $0.01 \mathrm{wt} \% \mathrm{Mn}, 0.19 \mathrm{wt} \% \mathrm{Fe}$ and $98.93 \% \mathrm{Al}$. The detailed procedures for producing the ceramic or metallic particulate reinforced composites using two-step stir casting technique have been reported earlier by Alaneme et al. $[33,34]$.

Uniaxial compression samples of $\varnothing 10$ and $15 \mathrm{~mm}$ length were machined from the as-cast aluminium-based composites. Axisymmetric compression testing was chosen over hot tensile testing because of the possibility of using smaller test samples and the advantage of achieving large plastic strains during deformation. A chromel-alumel (K-type) thermocouple was attached to the mid-span of the length of the compression samples using the wrap-round method [35]. The compression testing was performed on a Gleeble 3500 thermomechanical simulator at two different deformation temperatures $\left(220\right.$ and $\left.37^{\circ} \mathrm{C}\right)$, strain rates $(\sim 0.5$ and $5 \mathrm{~s}^{-1}$ ) and a total strain of $\sim 0.6$ or 1.2 . The two deformation temperatures were chosen to know the effect of warm working and hot working deformation temperature conditions on both composites while the two different strain rates were selected to study the effect of slow and high strain rate on the deformation behaviour of both composites. Graphite foil with nickel paste was placed between the ISO-T tungsten carbide flow stress anvil of the Gleeble machine and the composites samples to minimise frictional effects on flow stress. Prior to deformation, each of the samples was heated directly to the targeted deformation temperature and allowed to homogenise at this temperature for $180 \mathrm{~s}$. The resulting flow stress data 
were collected and analysed. To validate the tests, barrelling coefficient were determined following standard procedure for axisymmetric compression testing [36]. The deformed samples with barrelling coefficient greater than 1.1 were rejected and the tests were repeated. The flow stress data was not corrected for friction or adiabatic heating as this is already be a part of an on-going study which involves developing constitutive models and construction of processing maps.

The microstructures of the as-cast and deformed samples were taken using Leica DM 5000 optical microscope and Zeiss Field Emission Scanning Electron Microscope (FE-SEM). SEM images were taken in Backscattered electron (BSE) mode to determine the phases present in the alloys while Energy dispersive X-ray spectroscopy (EDX) analyses were also performed on selected phases to determine phase compositions. To analyse the deformed samples, they were sectioned parallel to the deformation axis and were mounted and polished following standard metallographic procedures. The final polishing was done using alumina suspension and the samples were etched using Weck's standard reagent.

\section{Results and discussion}

\subsection{Flow behaviour}

Figure 1 presents the flow stress of the composites deformed at different temperatures, strain rates, and global strains. The figure shows a clear dependency of the flow stress on the different deformation parameters and the reinforcing materials.

\subsubsection{Effect of working temperature}

From Figure 1, it is observed that higher working temperature decreased flow stress in $\mathrm{SiC}$ or $\mathrm{Ni}$ particulates reinforced AMCs. This trend is consistent with the general behaviour of metallic alloys and their composites when formed at different working temperatures. Higher working temperatures increase mobility of dislocation, diffusion rate, grain boundary migration which lower resistance of materials to deformation. In most metal working operation, working at temperature between 0.35 and $0.5 \mathrm{~T}_{\mathrm{m}}$ is often the standard practice because of the lower resistance to deformation [37]. However, deforming at warm working temperature $\left(<0.35 \mathrm{~T}_{\mathrm{m}}\right.$; where $\mathrm{T}_{\mathrm{m}}$ is the melting temperature) is becoming desirable due to low energy requirement and the possibility of achieving unique combination of strength and ductility. It is observed that despite deforming both composites at about $0.33 \mathrm{~T}_{\mathrm{m}}\left(220{ }^{\circ} \mathrm{C}\right)$ and $0.56 \mathrm{~T}_{\mathrm{m}}\left(370{ }^{\circ} \mathrm{C}\right)$, the shape of the stress-strain curves suggest either coupled dynamic recovery and work hardening at $220{ }^{\circ} \mathrm{C}$ or solely dynamic recovery at $370{ }^{\circ} \mathrm{C}$ as the dominant deformation mechanism. Dynamic recovery which is depicted by steady-state flow stress after the peak stress is reached [38] was noticeable at both working temperatures. However, with coupled effects of temperature, strain rates and strain, softening mechanisms deviated from dynamic recovery to dynamic recrystallisation at $370{ }^{\circ} \mathrm{C}$ (Fig. 1c) or work hardening at $220{ }^{\circ} \mathrm{C}$ (Fig. 1d). In Figure 1c, the broad peaks observed at $370{ }^{\circ} \mathrm{C}$ are signatures of dynamic recrystallisation while in Figure $1 \mathrm{~d}$, the gradual increase in flow stress beyond the yield stress indicates that rate of work hardening superintend over dynamically recovered restoration process.

\subsubsection{Effect of strain rate}

Figures $1 \mathrm{a}$ and $1 \mathrm{~b}$ show that flow stress is higher at the strain rate of $5 \mathrm{~s}^{-1}$ compared to $0.5 / \mathrm{s}^{-1}$ in $\mathrm{SiC}$ or $\mathrm{Ni}$ particulates reinforced AMCs. This trend agrees with the flow behaviour of most metallic alloys and aluminium based composites where increasing strain rates cause an increase flow stress due to an increase in the velocity mobile dislocations. Zong et al. [39] describe the relationship between strain rate and flow stress using equation (1), it shows that for materials with positive strain rate sensitivity, there is a direct relationship between strain rate and flow stress.

$$
\dot{\varepsilon}=\rho b A \sigma^{m}
$$

where $\dot{\varepsilon}$ is the strain rate, $\rho$ is the density, $b$ is the Burger's vector, $\mathrm{A}$ is a constant, $\sigma$ is flow stress and $m$ is the strain rate sensitivity parameter.

Comparatively, in Figures 1c and 1d, it is observed that flow stress is more responsive to strain and deformation temperature than strain rate. It is observed from Figure 1c that flow stress is higher at $0.5 \mathrm{~s}^{-1}$ than at $5 \mathrm{~s}^{-1}$ strain rate when a strain of 0.5 is exceeded in both composites. Similar response can be observed in $\mathrm{SiC}_{\mathrm{p}}$ reinforced $\mathrm{AMCs}$ (Fig. 1d). The AA6063- $\mathrm{Ni}_{\mathrm{p}}$ showed higher flow stress in sample deformed at $0.5 \mathrm{~s}^{-1}$ regardless of the strain. Further discussion on the influence of strain on flow stress in these AMCs is provided in Section 3.1.3.

Another important observation on the effects of strain rate on flow behaviour is the oscillation of flow stress at $0.5 \mathrm{~s}^{-1}$ rate. This is more conspicuous at deformation temperatures of $370{ }^{\circ} \mathrm{C}$ than at $220^{\circ} \mathrm{C}$. Flow oscillations at slow strain rates and high deformation have been reported as signatures of dynamic recrystallisation by some authors [40-42], while others have attributed the flow oscillations in aluminium alloys to dynamic strain ageing otherwise known as Portevin-Le-Chatelier (PLC) effect [43-45]. Jerky patterns and strain rate insensitivity are evidence of PLC effects and it has been reported in the aluminium alloys with high magnesium solutes. The matrix alloy used in the development of this AMCs is AA 6063 which contains $\sim 0.5 \mathrm{wt} \% \mathrm{Mg}$, hence the insensitivity to strain rate especially at $220^{\circ} \mathrm{C}$ in Ni particulate reinforced AMCs may have been caused by Portevin-Le Chatelier (PLC) effect. However, finding evidence to validate the occurrence of PLC effects in these AMCs is beyond the scope of this current study. 


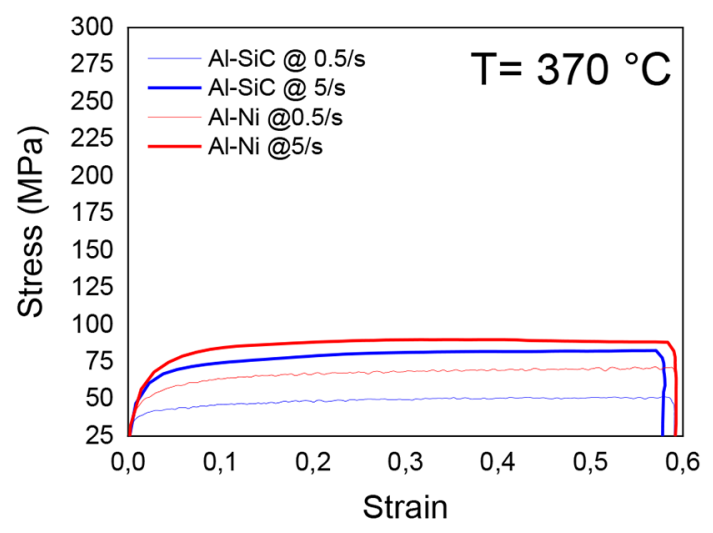

(a)

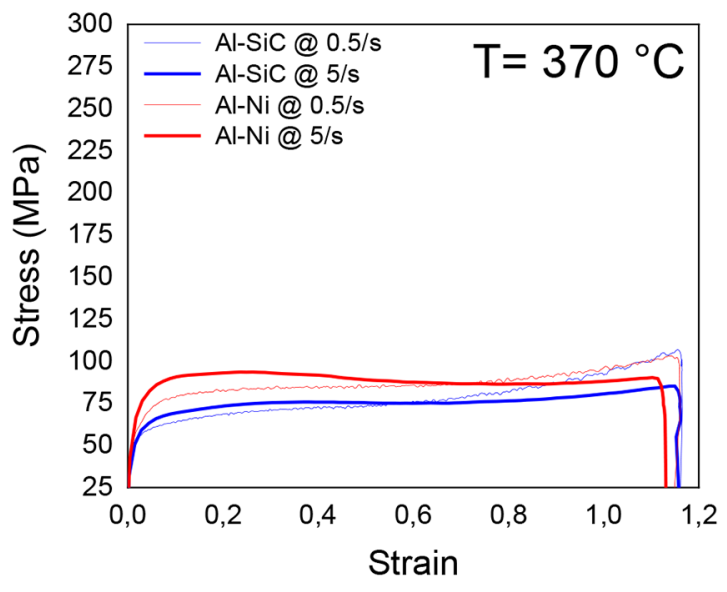

(c)

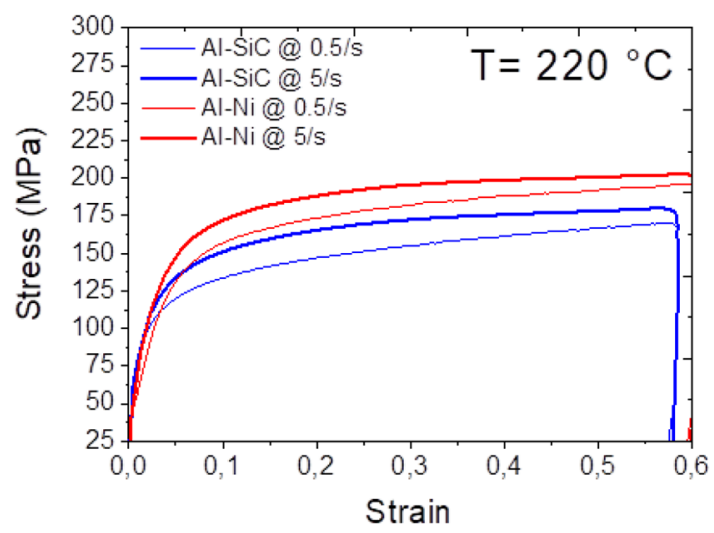

(b)

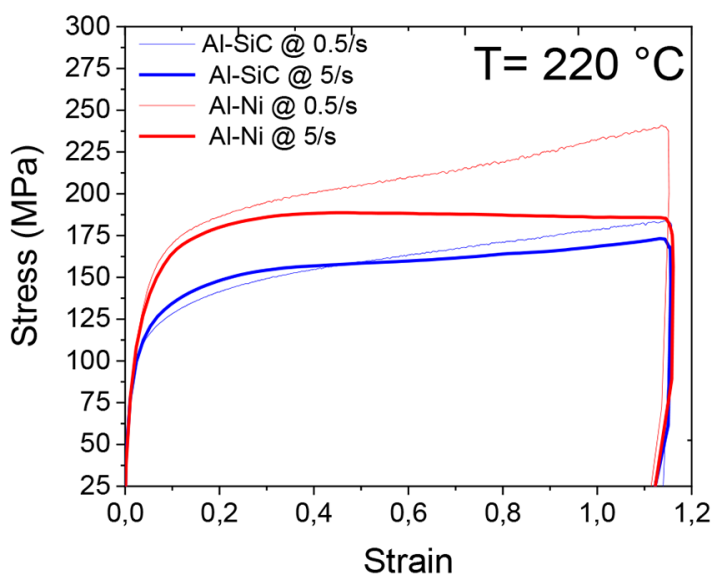

(d)

Fig. 1. Flow stress for uniaxially compressed aluminium matrix composites: (a) $\mathrm{T}=370{ }^{\circ} \mathrm{C}$ and $\varepsilon=0.6$; (b) $\mathrm{T}=220{ }^{\circ} \mathrm{C}$ and $\varepsilon=0.6$; (c) $\mathrm{T}=370{ }^{\circ} \mathrm{C}$ and $\varepsilon=1.2$ and $(\mathrm{d}) \mathrm{T}=220^{\circ} \mathrm{C}$ and $\varepsilon=1.2$.

\subsubsection{Effect of strain}

The increase in strain from 0.6 to 1.2 had significant effect on the flow stress of $\mathrm{AA} 6063-\mathrm{SiC}_{\mathrm{p}}$ and $\mathrm{AA} 6063-\mathrm{Ni}_{\mathrm{p}}$ composites. At the strain of 0.6 , the flow stress indicated dynamic recovery at $370{ }^{\circ} \mathrm{C}$ due to attainment of steadystate flow stress after the peak stress (Fig. 1a). However, work hardening was discernible at $220^{\circ} \mathrm{C}$ (Fig. 1b) in both composites since flow stress increased gradually up to a strain of 0.6 after the initial yielding which terminated at $\sim 0.5$ strain. As imposed strain increased beyond 0.6 at the working temperature of $370{ }^{\circ} \mathrm{C}$, broad peaks which suggest the occurrence of dynamic recrystallisation in both composites was followed by a rapid increase in flow stress up to a total strain of $\sim 1.2$. Similar trend was observed in AA6063-SiC $p$ deformed at $220{ }^{\circ} \mathrm{C}$ (Fig. 1d) when strain exceeded 0.6.

The increase in flow stress when strain exceeded 0.6 is caused by the frictional effect between the lateral surface of the sample and the tungsten carbide anvils. Li et al. [46] explained that despite the application of lubricants between the anvils and the samples, flow stress increased when strain is greater than 0.6 or 0.7 . They established that mitigating frictional effects on flow stress using lubricants is only effective up to a strain of 0.6. As strain exceeds this critical value during deformation, barrelling occurs in the sample and the lateral surface of the sample which is free of lubricants comes in contact with the anvil hence causing dynamic friction which increase the flow stress. The AA6063- $\mathrm{Ni}_{\mathrm{p}}$ deformed at $220{ }^{\circ} \mathrm{C}$ (Figure 1d) showed a completely different trend when compared to other flow stress in the figure, the flow stress increased gradually up the global strain of 1.2 after the initial yield at $\sim 0.05$ strain. This behaviour suggests work hardening as mechanism driving deformation under this condition.

\subsubsection{Effect of reinforcing particulates}

The choice of reinforcing materials has significant effect on the overall properties of AMCs [47,48]. Figure 1 shows that using nickel particulates as alternative reinforcements to $\mathrm{SiC}$ improved the high temperature compressive strength of the composites. The flow stress is consistently higher for AA6063- $\mathrm{Ni}_{\mathrm{p}}$ in comparison with $\mathrm{AA} 6063-\mathrm{SiC}_{\mathrm{p}}$ regardless of the working temperature, strain and strain rates. This suggest that for high-temperature load-bearing 


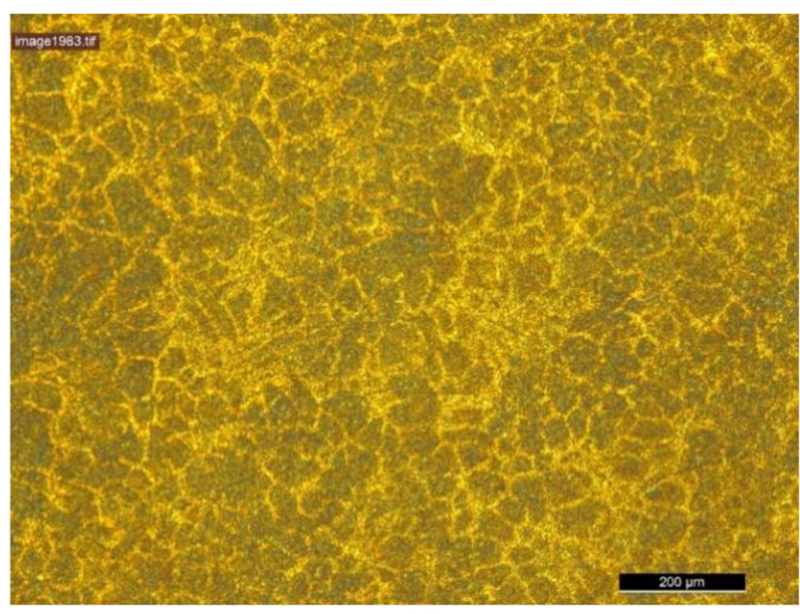

(a)

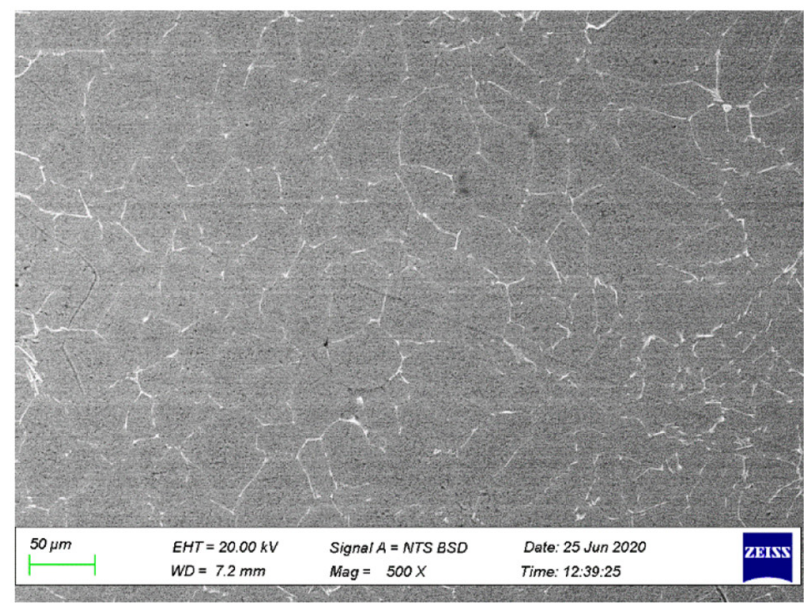

(c)

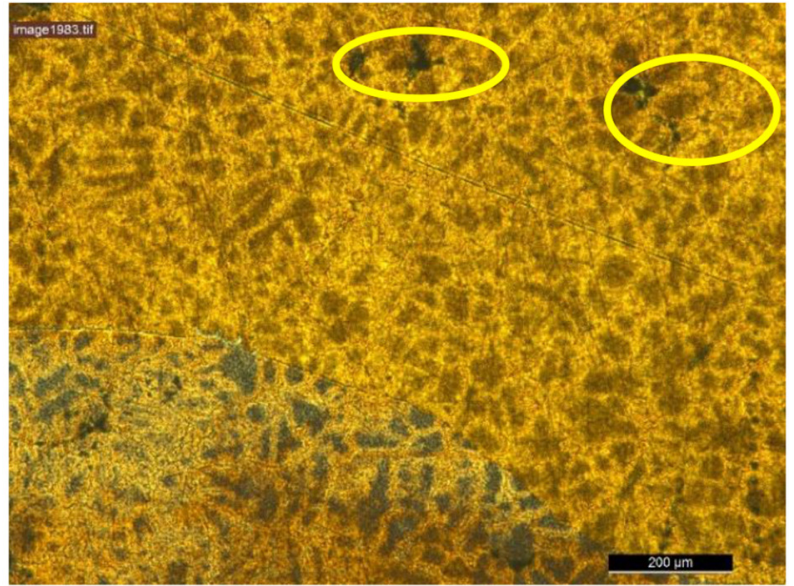

(b)

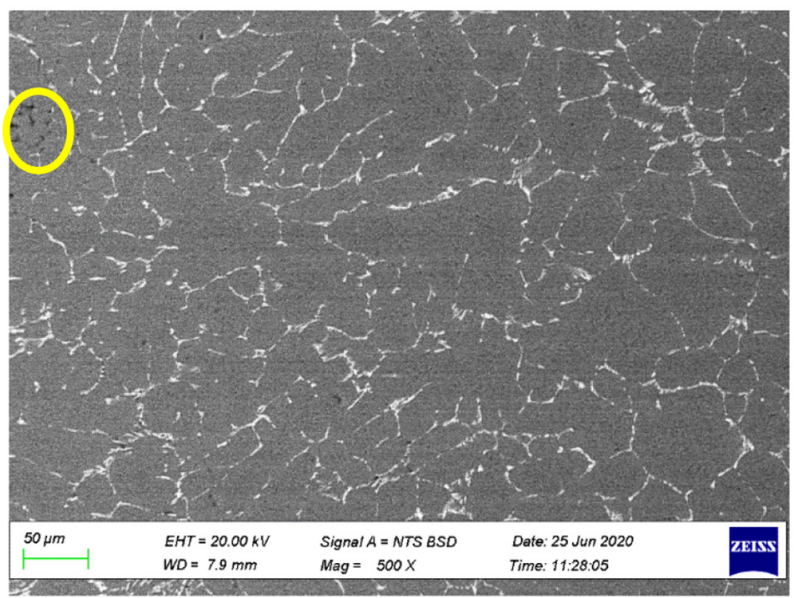

(d)

Fig. 2. Initial microstructures of $\mathrm{AA} 6063-\mathrm{SiC}_{\mathrm{p}}$ (a and c) and $\mathrm{AA} 6063-\mathrm{Ni}_{\mathrm{p}}$ (b and d) composites. Defects are marked in yellow ring. (a) AA $6063-\mathrm{SiC}_{\mathrm{p}}$ (b) AA6063-Ni $\mathrm{N}_{\mathrm{p}}$ (c) AA 6063-SiC (d) AA6063-Ni .

applications, AMCs with nickel metallic reinforcements are potentially superior to the conventional AMCs reinforced with ceramic particulates. This may be ascribed to improved wettability between the matrix material and the metallic reinforcement and improved load transfer between the AA 6063 matrix material and the Ni metallic reinforcement as established by researchers at ambient temperatures [49].

In contrast, the higher flow stress obtained in the $\mathrm{Ni}$ particulate reinforced composites is indicative of higher deformation resistance which is often not desirable when forming metallic materials into different profiles. Some researchers reported that higher resistance to deformation causes tool wear during metal working and may increase the overall cost of metal working [50-52]. To minimise forming cost of this Ni particulate reinforced composites, the most advantageous forming parameters determined using dynamic materials modelling approach becomes desirable and is being considered as the next phase of this work.

\subsection{Microstructural evolution}

It is notable from Sections 3.1.1-3.1.4 that several phenomena such as work hardening, dynamic recovery, and dynamic recrystallisation were probable mechanisms that influenced the behaviour of both composites when subjected to hot compression testing. To establish the factors that are responsible for higher hot compressive strength in Ni reinforced AMCs over $\mathrm{SiC}$ reinforced AMCs, the microstructural changes that occurred during deformation was evaluated.

This was done by comparing the initial microstructure (Fig. 2) of the composites with the post deformed microstructures. It was reported that the effective strain during deformation varies across the deformed samples $[53,54]$. Figure 3 shows a finite element simulation of the matrix aluminium alloy (AA 6063) using DEFORM 3D, it can be seen that effective strain was maximum at the centre of the sample due to strain variation across the sample during deformation. Similar FEM simulation 


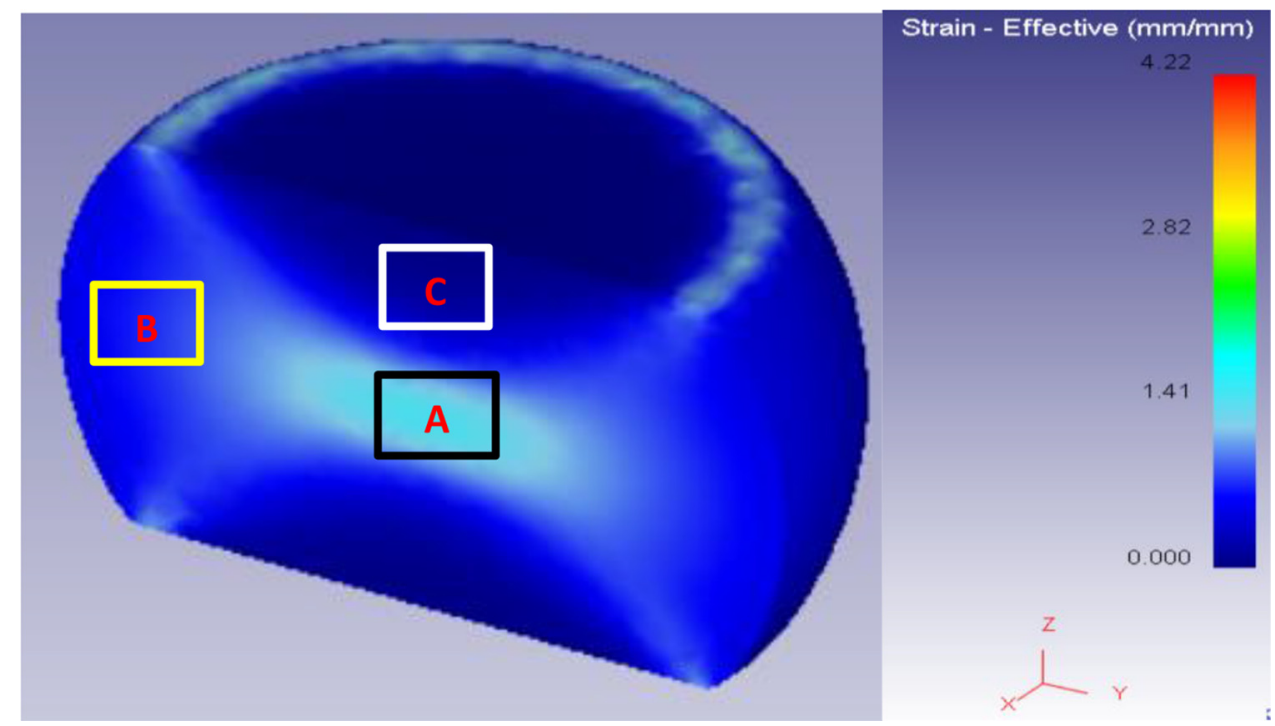

Fig. 3. DEFORM simulation of $\mathrm{Al} 6063$ alloy showing strain distribution across the deformed sample in positions A-centre; B- edge length and C-edge.

result was reported in Poletti et al. [55]. The microstructures were taken at the centre, edges and edgelength of the samples as indicated in Figure 3.

\subsubsection{Initial microstructure of the composites}

Figure 2 shows the optical micrograph and SEM-BSE images of as-cast $\mathrm{Ni}$ or $\mathrm{SiC}$ reinforced AMCs. The composite consisted of mainly equiaxed grains with well-defined grain boundaries. The as-cast microstructure of $\mathrm{AA}$ 6063-SiC $\mathrm{S}_{\mathrm{p}}$ shows more defined equiaxed grains in comparison with the as-cast microstructure of $\mathrm{AA}$ $6063-\mathrm{Ni}_{\mathrm{p}}$ composite. Both composites consist of two distinct phases (dark and light) with the light phase settling preferentially at the grain boundaries. The dark phase is the primary aluminium matrix $(\alpha-\mathrm{Al})$ phase, while the light phase is the secondary phase containing mainly $\mathrm{Mg}_{2} \mathrm{Si}$ precipitates and other intermetallic compounds such as AlFeSi [56-58]. Some voids (black spots of the Figs. $2 \mathrm{~b}$ and $2 \mathrm{~d}$ enclosed in yellow ring) and elongated grains are noticeable in the AA6063- $\mathrm{Ni}_{\mathrm{p}}$ composite. The dispersed reinforcing particulates are not seen in the as-cast images presented in Figure 2, suggesting the possible dissolution of some of the $\mathrm{Ni}$ particulates in the matrix alloy. However, EDX spot analyses on the phases present in the AA6063- $\mathrm{Ni}_{\mathrm{p}}$ composite (Fig. 4) confirmed the presence of $\mathrm{Ni}$ in the light phase. This suggest that the nickel particles may have settled preferentially at the grain boundaries. A reaction between $\mathrm{Al}$ and $\mathrm{Ni}$ is also possible such that $\mathrm{Al}$ $\mathrm{Ni}$ intermetallic is formed in situ [59]. Further studies are on-going to fully understand the reinforcement-matrix interaction during production of the AMCs.

\subsubsection{Post deformed microstructures in region $A$}

Figure 5 shows the deformed micrographs of AA6063-SiC composite taken in the region with the maximum local strain. It can be seen that in comparison with the initial microstructure (Fig. 2a), the primary $\alpha$-Al phase became elongated and thinned regardless of the deformation temperature, strain and strain rate. The elongated phase is perpendicular to the compression axis and the elongation and thinning is higher at higher deformation temperature and strain. At the temperature of $370{ }^{\circ} \mathrm{C}$ the $\alpha$-Al phase becomes softer and more amenable to deformation. The samples deformed at higher strain of 1.2 combined with higher strain rate (Figs. 5b,e and 5f) had thinner $\alpha-\mathrm{Al}$ phase in comparison with other samples (Figs. 5a,c and 5d) where elongated $\alpha$-Al phase is thick and partially equiaxed grains can be observed. The elongated and thinned $\alpha-\mathrm{Al}$ phase is an evidence of strain bands which confirmed that deformation was more intense at the centre of the composite's samples. Agglomerated silicon carbide particles are seen in Figure 5e suggesting that these particles were not homogenously dispersed within the matrix. This agglomeration of silicon carbide particles was not captured in the as-cast initial microstructure (Fig. 2a) or in the post deformed microstructures taken in other regions of the composite samples.

The SEM images of the AA6063-SiC $\mathrm{A}_{\mathrm{p}}$ composite (Fig. 6) taken at higher magnification corroborates observations in the optical images. The well-defined equiaxed grains in the initial microstructures were severely distorted and strain bands were more conspicuous at higher strain rate $\left(5 \mathrm{~s}^{-1}\right)$ and strain of 1.2 (Figs. $6 \mathrm{c}$ and $6 \mathrm{~d}$ ). Small silicon carbide particles are visible in Figure $7 \mathrm{~b}$ but were absent in images of other samples. This supports the notion that the silicon carbide particles were not evenly dispersed 

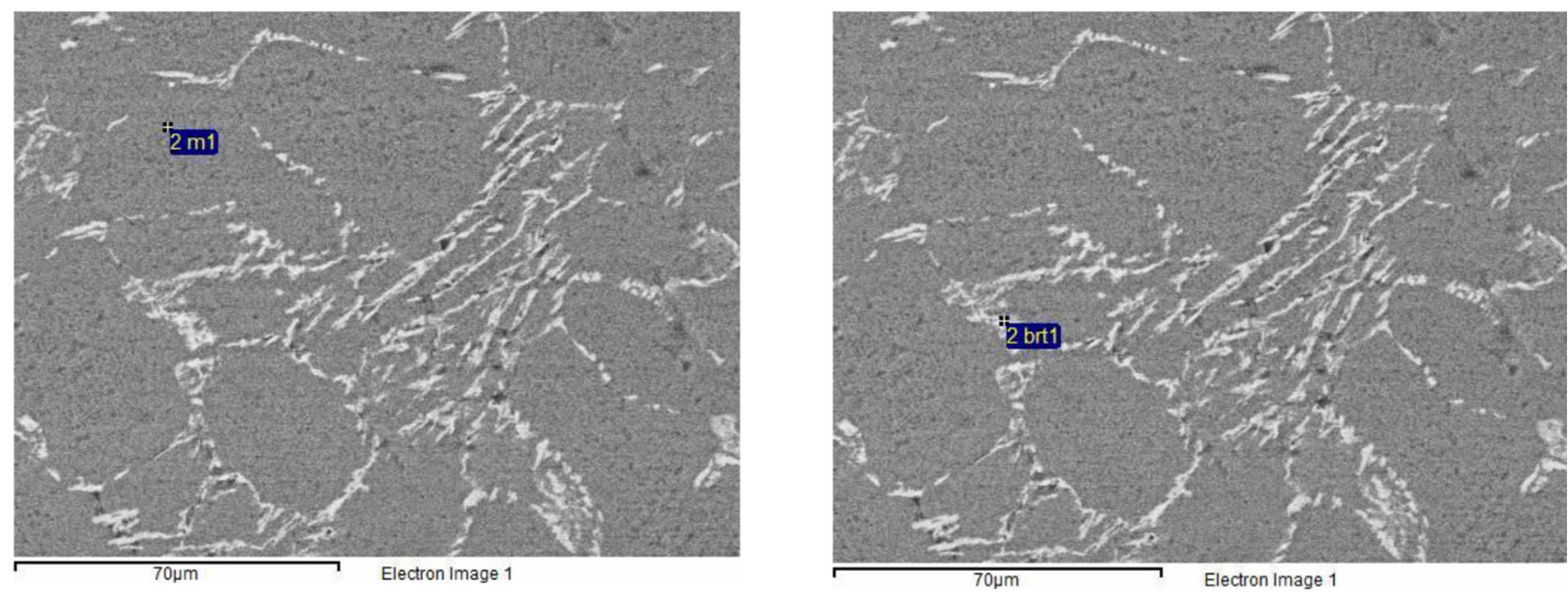

\begin{tabular}{|l|l|l|}
\hline Element & Weight $\%$ & Atomic\% \\
\hline \hline $\mathrm{O} \mathrm{K}$ & 8.24 & 13.25 \\
\hline $\mathrm{Mg} \mathrm{K}$ & 0.54 & 0.57 \\
\hline \hline $\mathrm{Al} \mathrm{K}$ & 89.57 & 85.41 \\
\hline $\mathrm{Mn} \mathrm{K}$ & 1.10 & 0.51 \\
\hline Fe K & 0.55 & 0.25 \\
\hline \hline Totals & 100.00 \\
\hline
\end{tabular}

\begin{tabular}{|l|l|l|}
\hline Element & Weight $\%$ & Atomic\% \\
\hline \hline $\mathrm{O}$ K & 5.09 & 9.46 \\
\hline $\mathrm{Mg} \mathrm{K}$ & 0.43 & 0.52 \\
\hline $\mathrm{Al} \mathrm{K}$ & 69.62 & 76.77 \\
\hline $\mathrm{Si} \mathrm{K}$ & 1.00 & 1.06 \\
\hline $\mathrm{Mn} \mathrm{K}$ & 0.36 & 0.19 \\
\hline Fe K & 2.88 & 1.54 \\
\hline Ni K & 20.63 & 10.46 \\
\hline \hline Totals & 100.00 \\
\hline
\end{tabular}

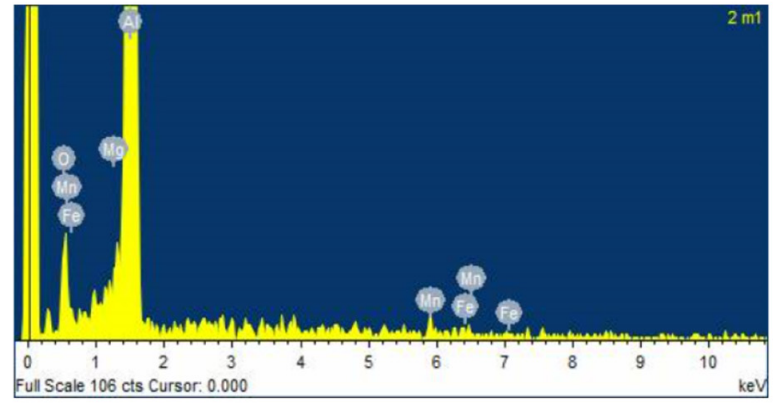

(a)

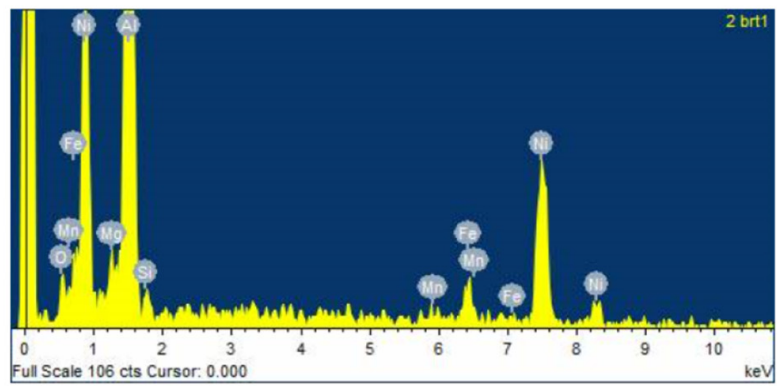

(b)

Fig. 4. EDX analysis showing composition of (a) matrix and (b) nickel in the secondary phase.

in the matrix AA6063 alloy. Figure 7 show the result obtained from EDX spot analysis confirming the presence of $\mathrm{SiC}$ particles in the $\mathrm{AA} 6063-\mathrm{SiC}_{\mathrm{p}}$ composite as indicated in Figures 5e and 6b.

The post deformed microstructures taken at the centre of AA $6063-\mathrm{Ni}_{\mathrm{p}}$ composites is presented in Figure 8. Similar to AA6063-SiC ${ }_{p}$ composites (Fig. 5), elongated $\alpha$-Al phase which is perpendicular to the compression direction can be seen, especially at higher deformation temperature of $370{ }^{\circ} \mathrm{C}$, strain rate $\left(5 \mathrm{~s}^{-1}\right)$ and strain of 1.2 (Fig. 6d). Considerable amount of partially equiaxed $\alpha$-Al grains can be seen in samples deformed at lower strain of 0.6 (Figs. 8a and $8 \mathrm{e}$ ). Despite observing strain bands in the centre region of both $\mathrm{AA} 6063-\mathrm{SiC}_{\mathrm{p}}$ and $\mathrm{AA} 6063-\mathrm{Ni}_{\mathrm{p}}$ deformed samples, the degree of straining in region $\mathrm{A}$ appears to be higher in the AA6063- $\mathrm{Ni}_{\mathrm{p}}$ composites since the elongated grains in this composite are finer than in $\mathrm{AA} 6063-\mathrm{SiC}_{\mathrm{p}}$. This is obvious when comparing $\mathrm{AA}$ 6063- $\mathrm{SiC}_{\mathrm{p}}$ (Fig. 5d) to $\mathrm{AA} 6063-\mathrm{Ni}_{\mathrm{p}}$ (Fig. 8e) or AA6063-SiC $\mathrm{p}_{\mathrm{p}}$ (Fig. 5a) to AA6063-Ni $\mathrm{p}_{\mathrm{p}}$ (Fig. 8b). These composites were deformed under similar experimental conditions. The fine microstructural features observed in the $\mathrm{AA} 6063-\mathrm{Ni}_{\mathrm{p}}$ may explain the higher flow stress seen in this composite grade. Fine microstructure enhances branching of dislocation and thus increase the flow stress $[60,61]$.

The SEM images taken from region $\mathrm{A}$ of these composites is presented in Figure 9. The observed features support the observations from the optical micrographs. Strain bands are more obvious in samples subjected to deformation at higher strain rate and strain. At lower 


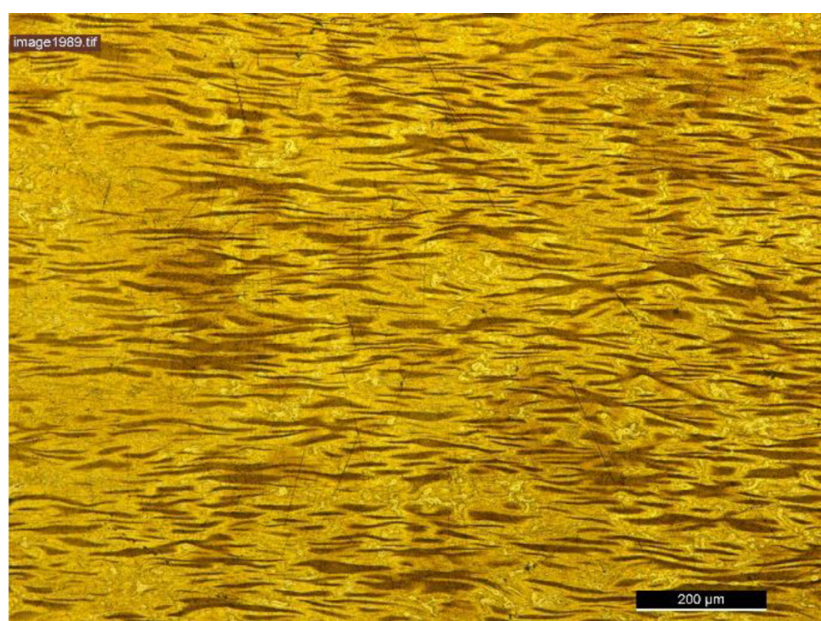

(a)

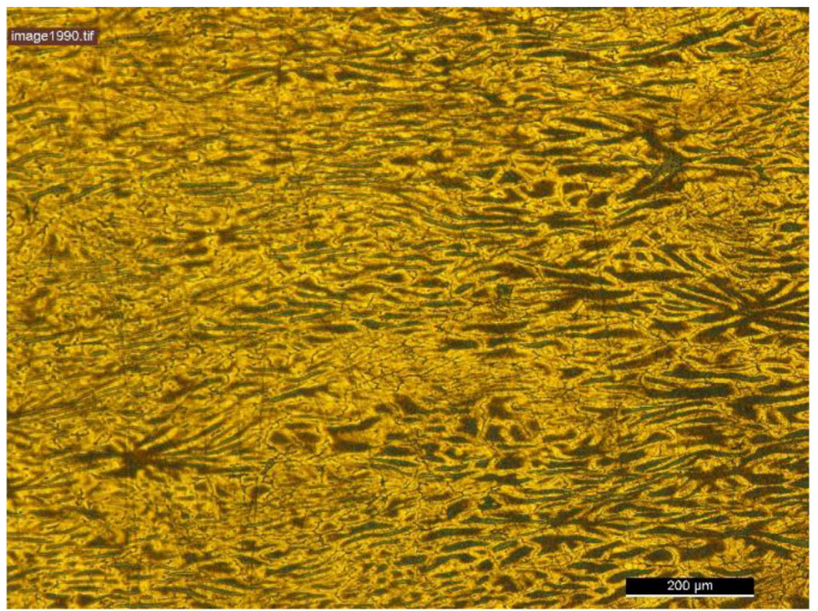

(c)

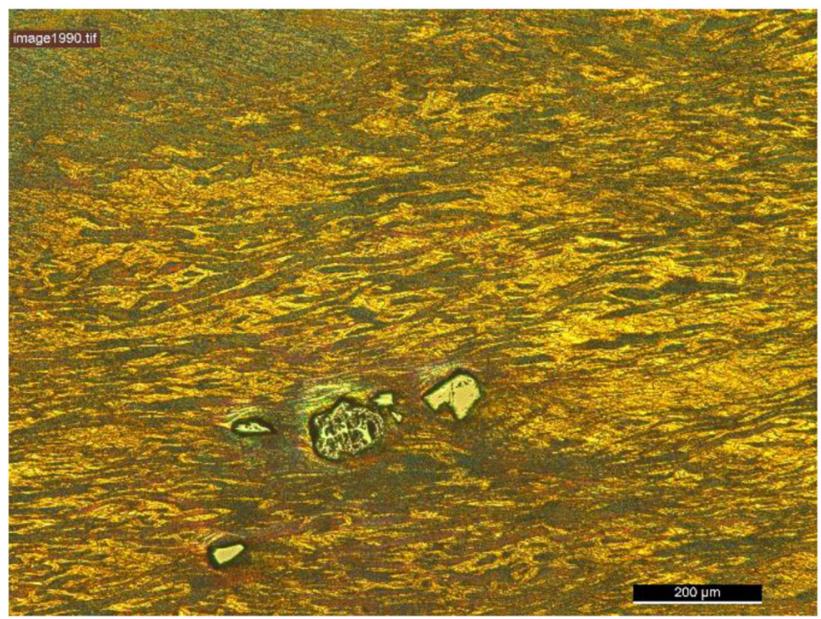

(e)

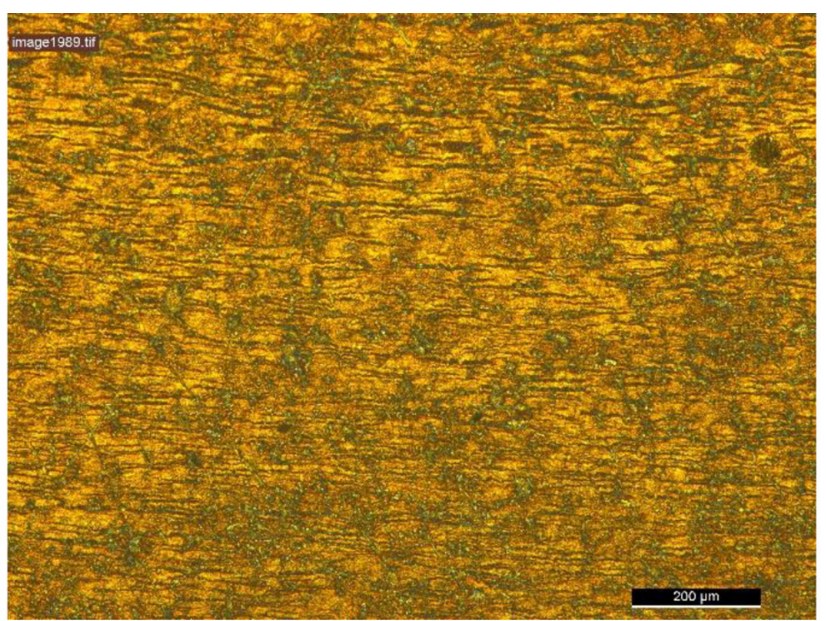

(b)

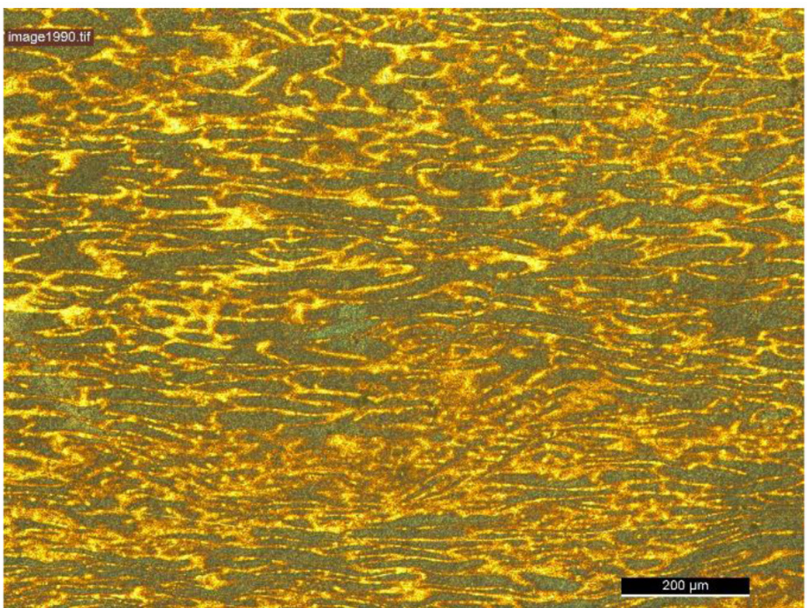

(d)

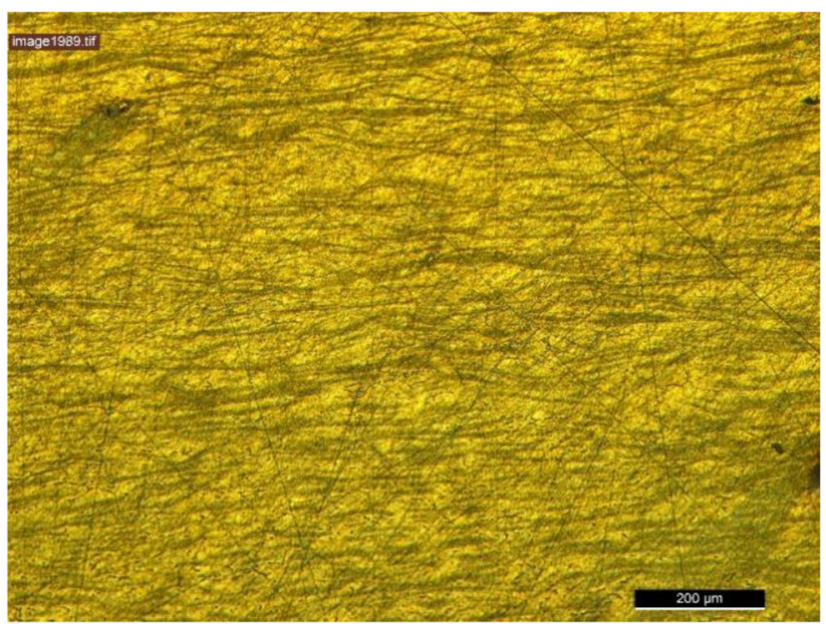

(f)

Fig. 5. Optical images of $\mathrm{AA} 6063-\mathrm{SiC}_{\mathrm{p}}$ composites taken in region $\mathrm{A}$ of the deformed samples: (a) $\mathrm{T}=370^{\circ} \mathrm{C}, \dot{\varepsilon}=5 \mathrm{~s}^{-1} \& \varepsilon=0.6$; (b) $\mathrm{T}=370{ }^{\circ} \mathrm{C}, \dot{\varepsilon}=5 \mathrm{~s}^{-1} \& \varepsilon=1.2 ;$ (c) $\mathrm{T}=220^{\circ} \mathrm{C}, \dot{\varepsilon}=0.5 \mathrm{~s}^{-1} \& \varepsilon=0.6$; (d) $\mathrm{T}=220{ }^{\circ} \mathrm{C}, \dot{\varepsilon}=5 \mathrm{~s}^{-1} \& \varepsilon=0.6 ;(\mathrm{e}) \mathrm{T}=220^{\circ} \mathrm{C}, \dot{\varepsilon}=0.5 \mathrm{~s}^{-1} \&$ $\varepsilon=1.2 ;$ and (f) $\mathrm{T}=220^{\circ} \mathrm{C}, \dot{\varepsilon}=5 \mathrm{~s}^{-1} \& \varepsilon=1.2$. 


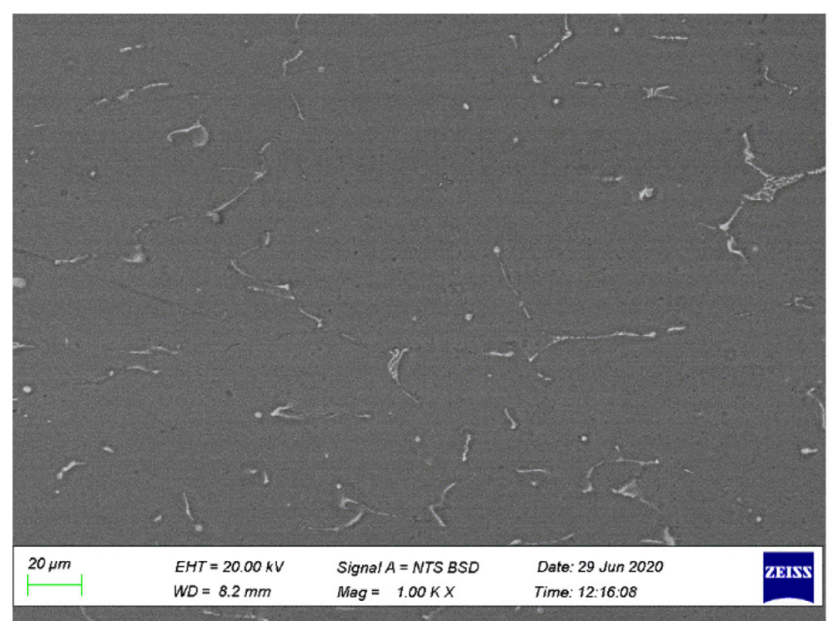

(a)

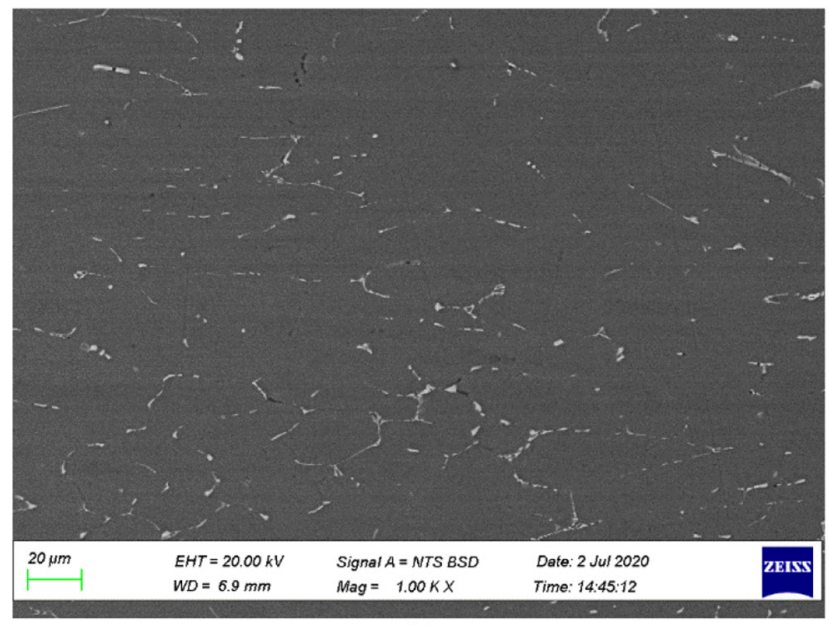

(c)

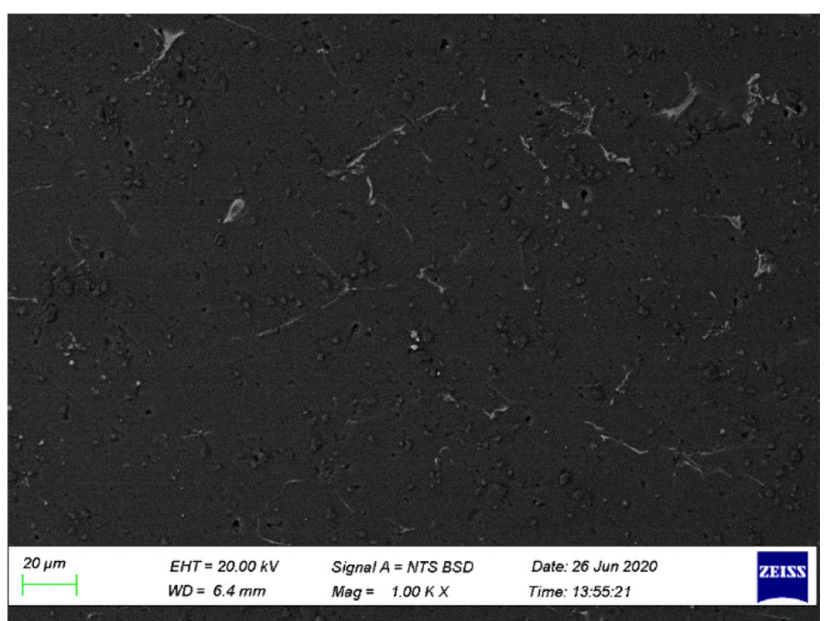

(b)

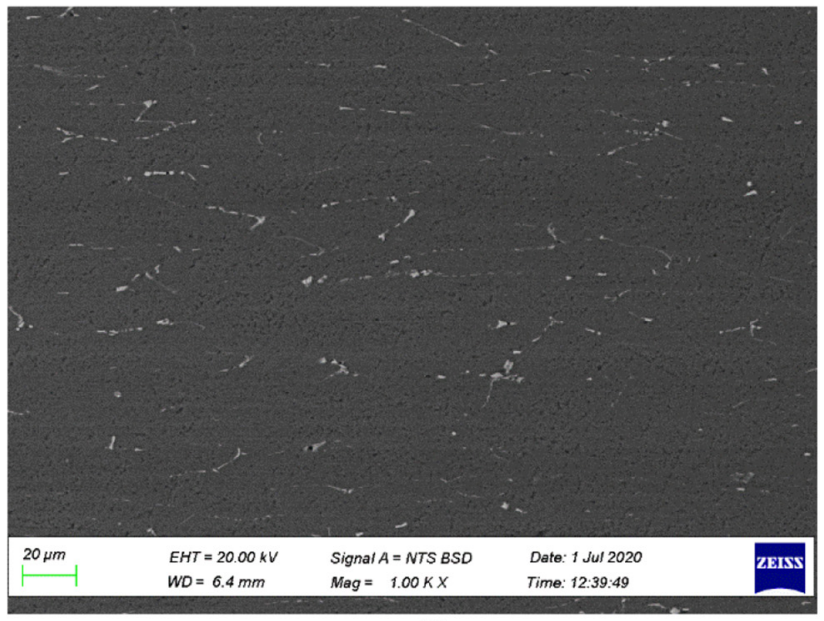

(d)

Fig. 6. SEM-BSE images of $\mathrm{AA} 6063-\mathrm{SiC}_{\mathrm{p}}$ composite taken in region $\mathrm{A}$ of the deformed samples (a) $\mathrm{T}=370{ }^{\circ} \mathrm{C}, \dot{\varepsilon}=0.5 \mathrm{~s}^{-1} \& \varepsilon=0.6$; (b) $\mathrm{T}=370{ }^{\circ} \mathrm{C}, \dot{\varepsilon}=5 \mathrm{~s}^{-1} \& \varepsilon=1.2 ;$ (c) $\mathrm{T}=220^{\circ} \mathrm{C}, \dot{\varepsilon}=0.5 \mathrm{~s}^{-1} \& \varepsilon=0.6$; and (d) $\mathrm{T}=220{ }^{\circ} \mathrm{C}, 5 \mathrm{~s}^{-1} \& \varepsilon=1.2$.

strain and strain rate, distorted equiaxed grains dominated by light phase at the grain boundaries are seen (Figs. 9a and 9c) but these equiaxed grains are compressed into particles forming bands parallel to the compression direction at higher strain and strain rate. When comparing the SEM images obtained in both composites, it is observed that the AA $6063-\mathrm{Ni}_{\mathrm{p}}$ composites showed evenly dispersed light phase within the $\alpha$-Al matrix. As noted earlier, the light phase in this composite is believed to be rich in both intermetallic precipitates and nickel particles that can effectively pose restrictions to dislocation motion, thereby causing superior high temperature compressive strength observed in the AA $6063-\mathrm{Ni}_{\mathrm{p}}$ composites over the AA $6063-\mathrm{SiC}_{\mathrm{p}}$ composites.

Since the microstructural features obtained in the centre region of the samples could not provide sufficient evidence to validate the mechanisms influencing the deformation behaviour of the composites, micrographs were taken in other regions ( $\mathrm{B}$ and $\mathrm{C}$ ) of the composites need to be analysed and discussed. This is presented in Section 3.2.3.

\subsubsection{Post deformed microstructures in region $B$ and $C$}

Figure 10 shows selected optical micrographs of both composites taken at different regions. Similar features were observed in the images of samples deformed under similar deformation conditions. For AA6063-SiC $\mathrm{p}_{\mathrm{p}}$ composite, elongated and partially equiaxed grains can be observed in Figures 10a and 10b while for AA6063- $\mathrm{Ni}_{\mathrm{p}}$ composite, a mix of partial elongated $\alpha-\mathrm{Al}$, partial and fully globularised $\alpha$-Al can be seen in Figures $10 \mathrm{c}$ and 10d. Despite the similarity in the observed features in the different regions of composite, it is evident that the microstructure of AA6063$\mathrm{Ni}_{\mathrm{p}}$ and $\mathrm{AA} 6063-\mathrm{SiC}_{\mathrm{p}}$ composites taken in region $\mathrm{B}$ is coarser than region $\mathrm{C}$. These variations from one region to another in the same composite sample confirm the 

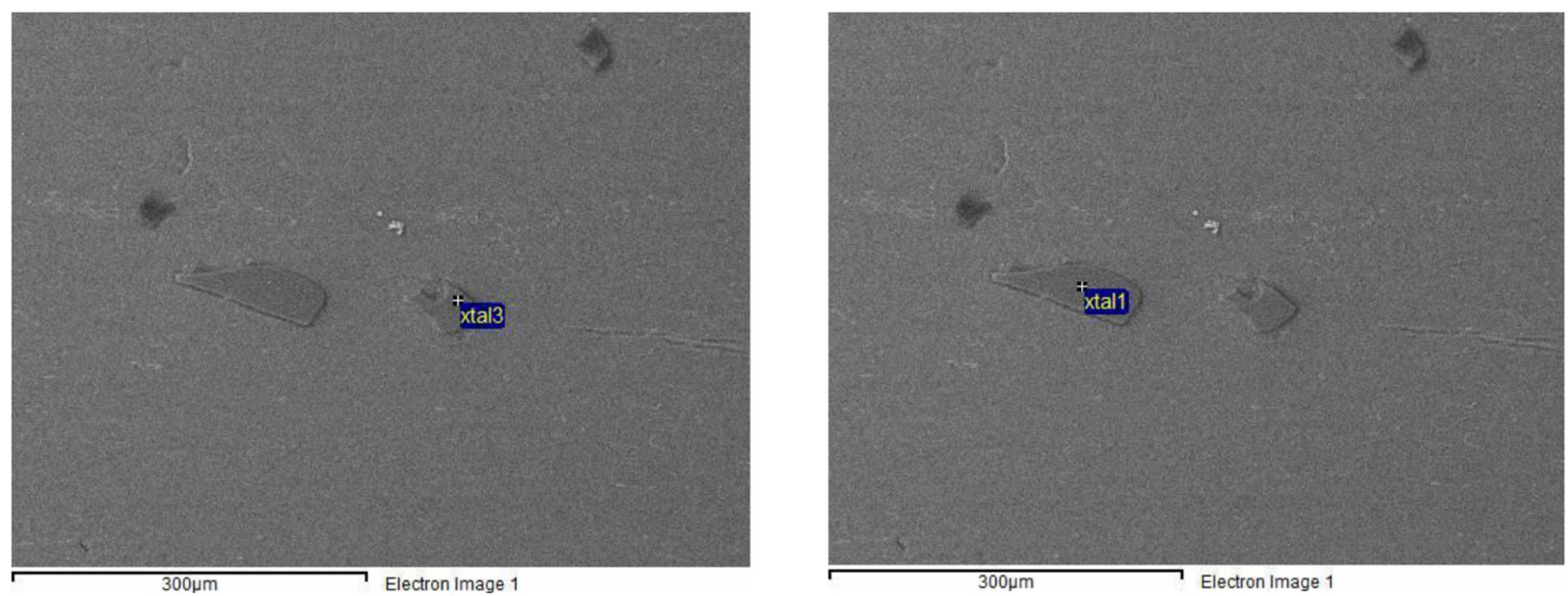

\begin{tabular}{|l|l|l|}
\hline Element & Weight\% & Atomic\% \\
\hline \hline $\mathrm{C} \mathrm{K}$ & 73.76 & 86.80 \\
\hline Si K & 26.24 & 13.20 \\
\hline \hline Totals & 100.00 \\
\hline
\end{tabular}

\begin{tabular}{|l|l|l|}
\hline Element & Weight $\%$ & Atomic $\%$ \\
\hline \hline C K & 81.15 & 90.97 \\
\hline Si K & 18.85 & 9.03 \\
\hline \hline Totals & 100.00 \\
\hline
\end{tabular}

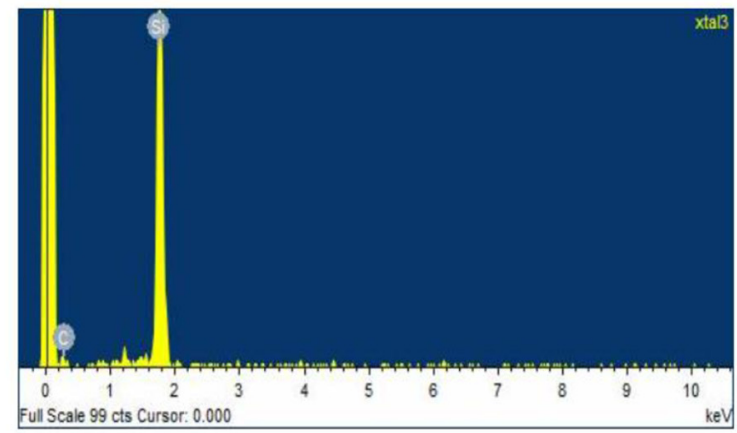

(a)

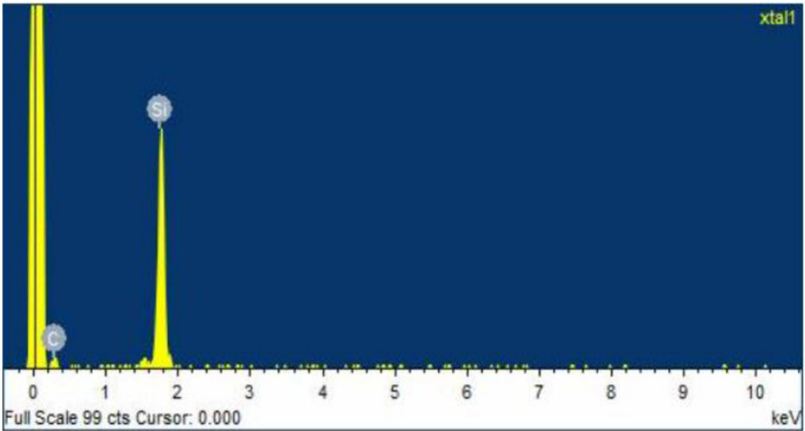

(b)

Fig. 7. EDX analysis confirming the presence of silicon carbide particulates in (a and b).

microstructural heterogeneity in the composites and hence necessitates studies focusing on optimisation of deformation parameters for the achieving homogenous microstructures during hot working of these composites. Since Region B has the largest area on the deformed samples. SEM images were taken in this region on both composites for comparison.

Figures 11 and 12 show selected SEM images of deformed AA6063-SiC $\mathrm{S}_{\mathrm{p}}$ composite and AA6063- $\mathrm{Ni}_{\mathrm{p}}$ composites samples under different conditions. The AA6063- $\mathrm{Ni}_{\mathrm{p}}$ composite shows more distinct network of the light phase containing the intermetallic precipitates and nickel particulates in comparison with AA6063-SiC composite. The light phase is sparsely dispersed within the matrix of the AA6063-SiC $\mathrm{p}_{\mathrm{p}}$ composite. The higher fraction of the light phase in regions $\mathrm{A}$ and $\mathrm{B}$ of the $\mathrm{AA} 6063-\mathrm{Ni}_{\mathrm{p}}$ composite over the $\mathrm{AA} 6063-\mathrm{SiC}_{\mathrm{p}}$ composite further corroborates the superior strength exhibited by the AA6063- $\mathrm{Ni}_{\mathrm{p}}$ composite.

To validate the underlying deformation mechanisms suggested on the flow curves presented in Figure 1, microstructural features which are signatures of deformation mechanisms were sought from Figures 11 and 12. It can be seen that considerable number of $\alpha$-Al globules and equiaxed grains can be found in Figure 12e $\left(\mathrm{AA} 6063-\mathrm{SiC}_{\mathrm{p}}\right.$, $220{ }^{\circ} \mathrm{C}, 0.5 \mathrm{~s}^{-1}$ and 0.6 strain) and $13 \mathrm{a}-\mathrm{d}\left(\mathrm{AA} 6063-\mathrm{Ni}_{\mathrm{p}}\right.$, $370{ }^{\circ} \mathrm{C}, 0.5 \mathrm{~s}^{-1}$ and 0.6 strain; AA $6063-\mathrm{Ni}_{\mathrm{p}}, 370{ }^{\circ} \mathrm{C}, 0.5 \mathrm{~s}^{-1}$ and 0.6 strain; and $\mathrm{AA} 6063-\mathrm{Ni}_{\mathrm{p}}, 370{ }^{\circ} \mathrm{C}, 5 \mathrm{~s}^{-1}$ and 1.2 strain). These globules are signatures of geometric dynamic recrystallisation which confirm the occurrence of dynamic recrystallisation in both composites as suggested by the broad peaks observed in Figure 1c and oscillating flow stress of AA $6063-\mathrm{Ni}_{\mathrm{p}}, 370{ }^{\circ} \mathrm{C}$ and 0.6 strain (Fig. 1a). The elongated grains observed in $\mathrm{AA} 6063-\mathrm{SiC}_{\mathrm{p}}$ 


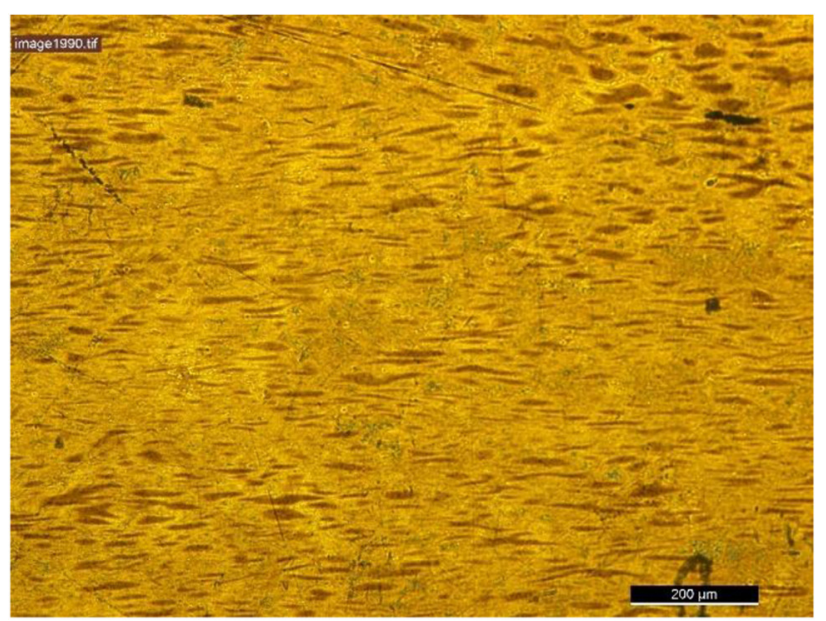

(a)

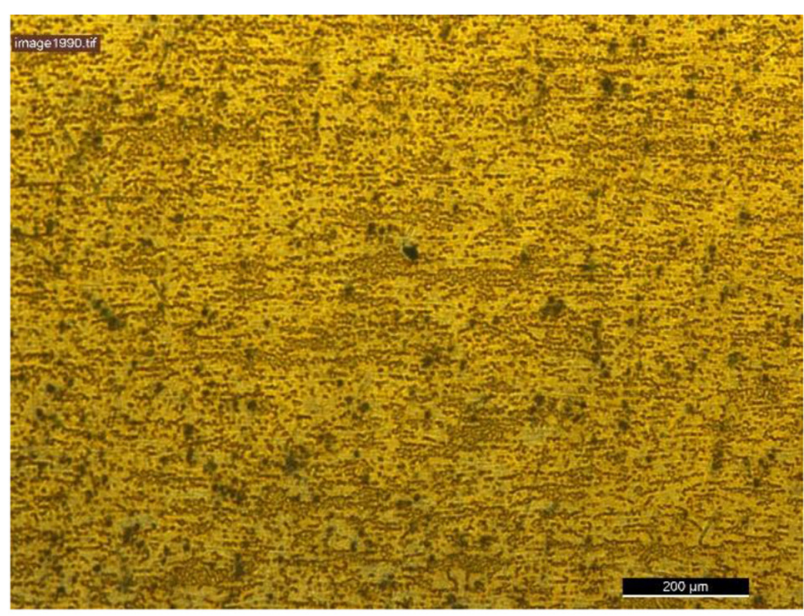

(c)

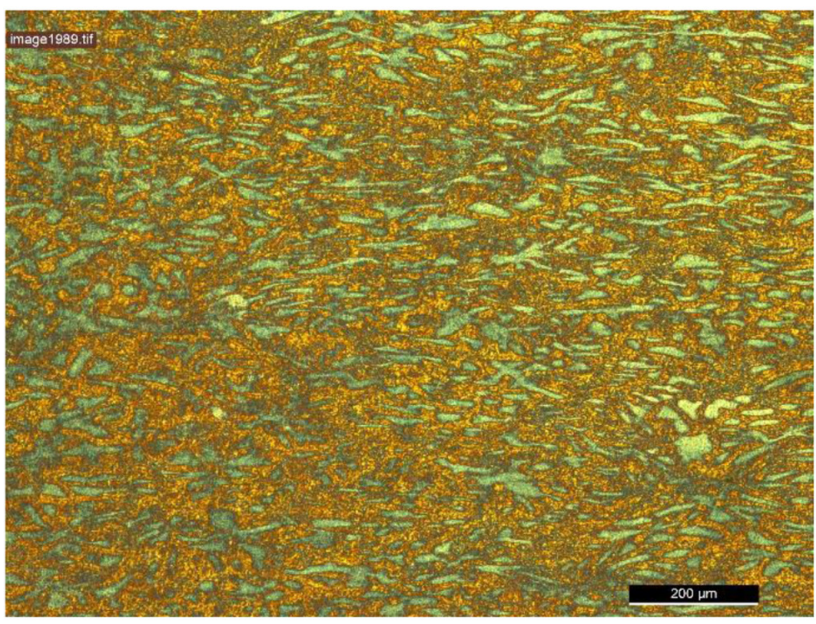

(e)

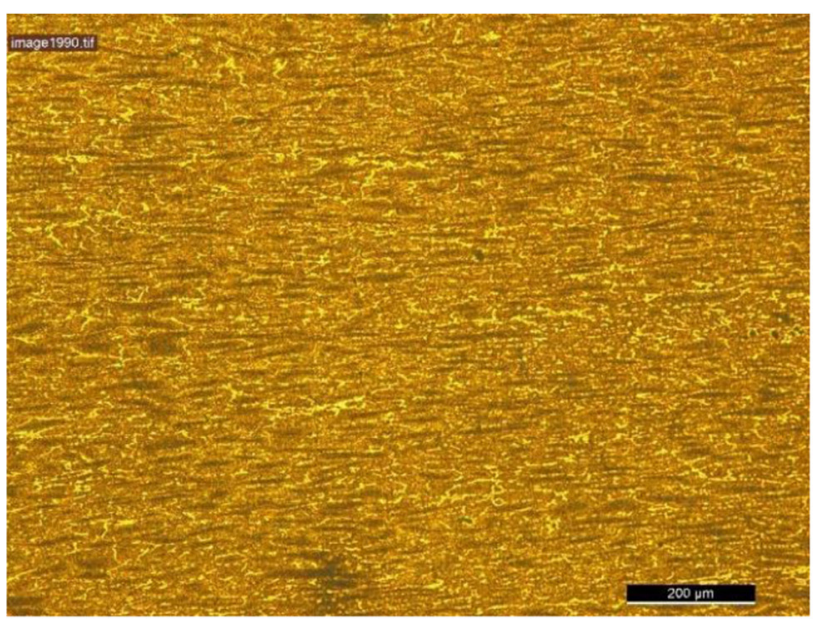

(b)

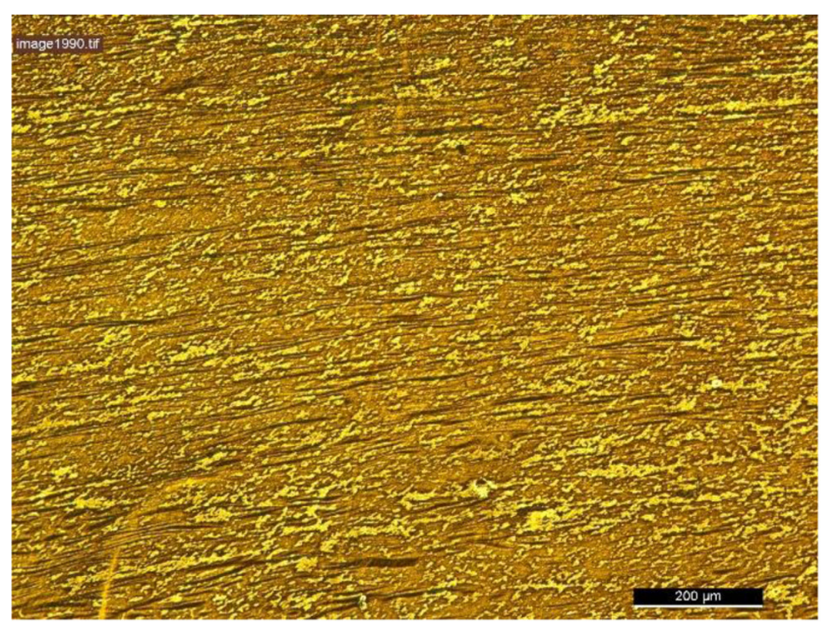

(d)

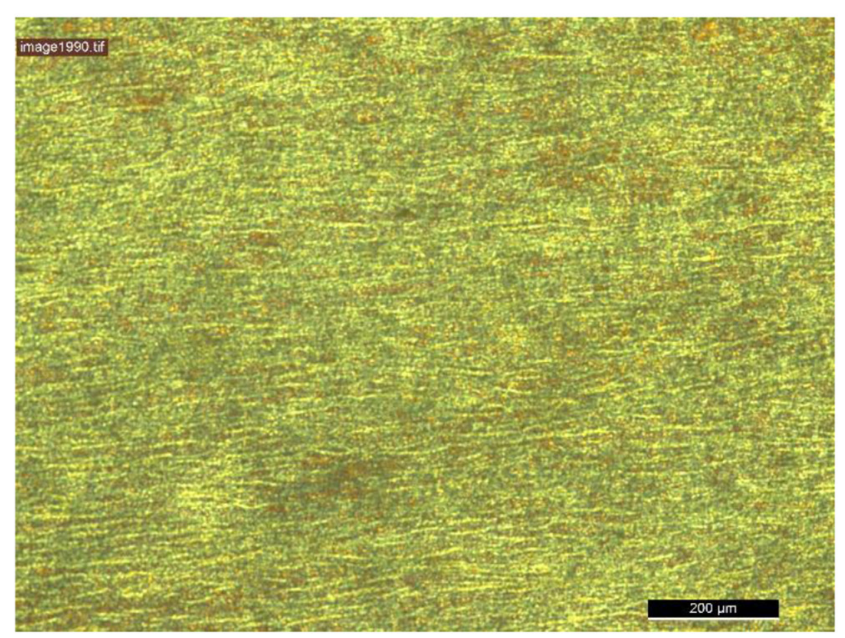

(f)

Fig. 8. Optical images of AA $6063-\mathrm{Ni}_{\mathrm{p}}$ composites taken in region A of the deformed samples (a) $\mathrm{T}=370^{\circ} \mathrm{C}, \dot{\varepsilon}=0.5 \mathrm{~s}^{-1} \& \varepsilon=0.6$; (b) $\mathrm{T}=370{ }^{\circ} \mathrm{C}, \dot{\varepsilon}=5 \mathrm{~s}^{-1} \& \varepsilon=0.6 ;(\mathrm{c}) \mathrm{T}=370^{\circ} \mathrm{C}, \dot{\varepsilon}=0.5 \mathrm{~s}^{-1} \& \varepsilon=1.2$ (d) $\mathrm{T}=370{ }^{\circ} \mathrm{C}, \dot{\varepsilon}=5 \mathrm{~s}^{-1} \& \varepsilon=1.2 ;(\mathrm{e}) \mathrm{T}=220^{\circ} \mathrm{C}, \dot{\varepsilon}=5 \mathrm{~s}^{-1} \&$ $\varepsilon=0.6$. (f) $\mathrm{T}=220^{\circ} \mathrm{C}, \dot{\varepsilon}=5 \mathrm{~s}^{-1} \& \varepsilon=1.2$. 


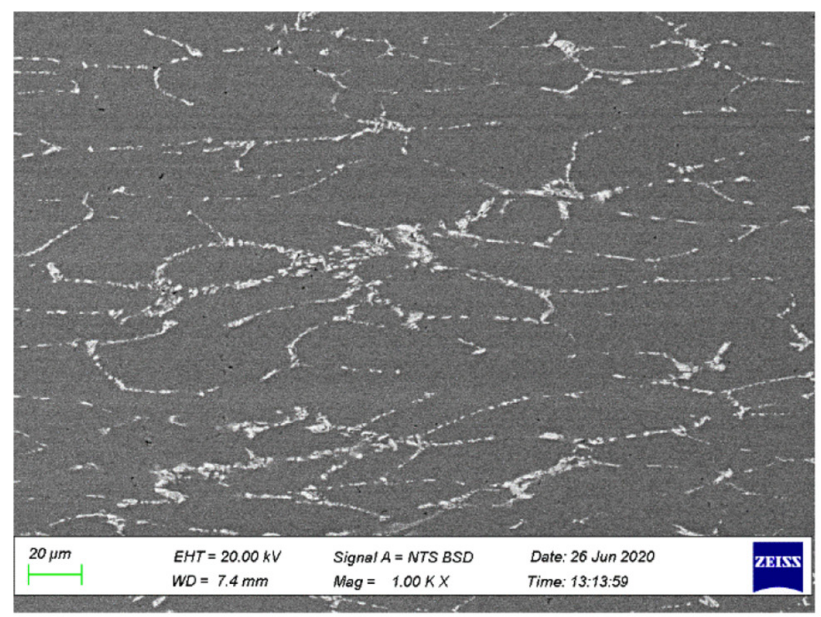

(a)

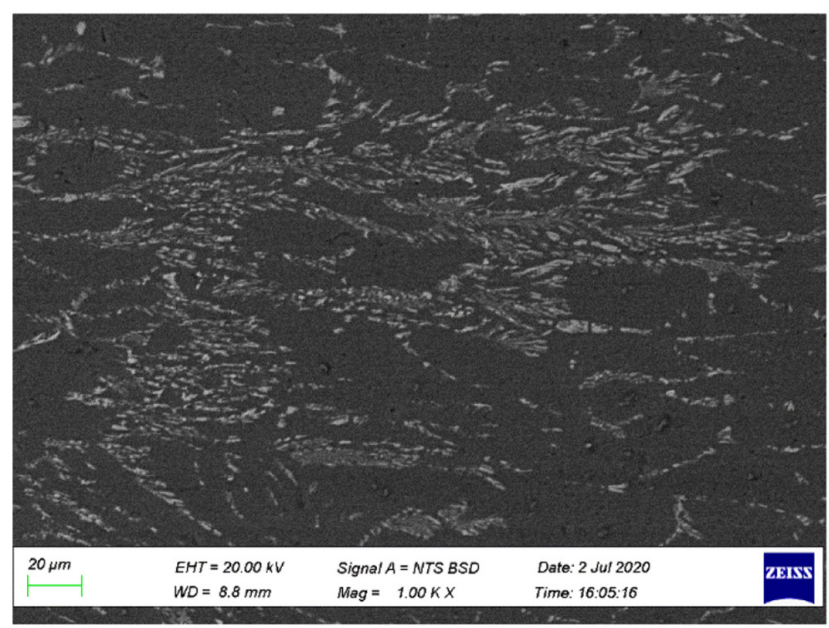

(c)

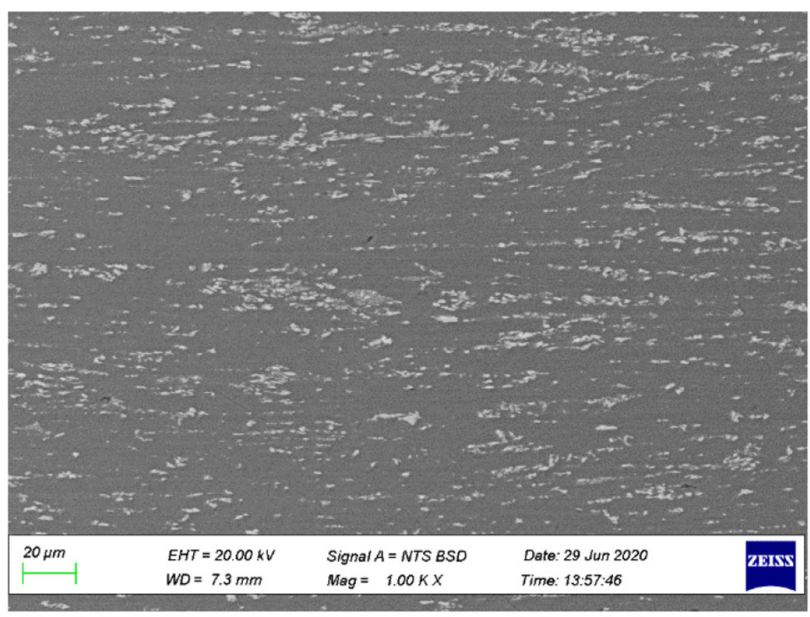

(b)

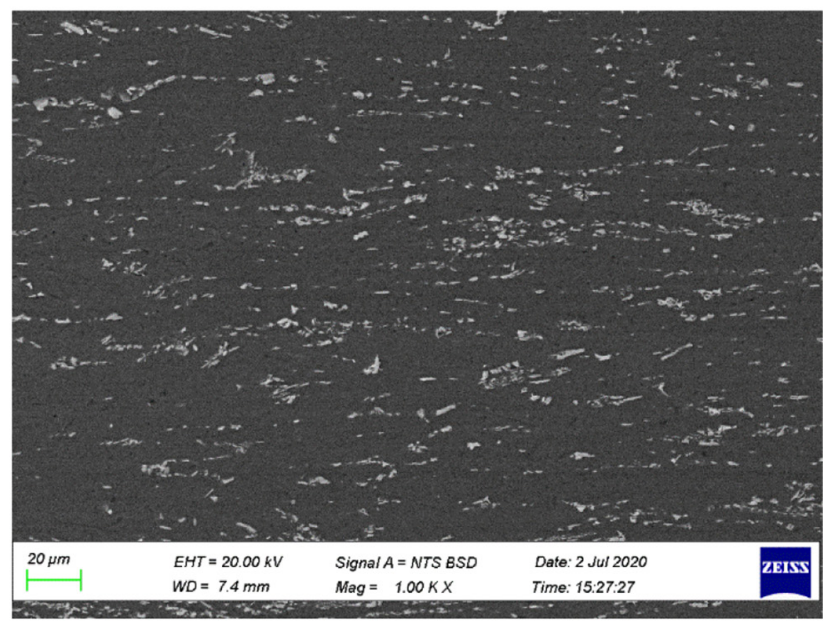

(d)

Fig. 9. SEM-BSE images AA $6063-\mathrm{Ni}_{\mathrm{p}}$ composites taken in region $\mathrm{A}$ of the deformed samples: (a) $\mathrm{T}=370^{\circ} \mathrm{C}, \dot{\varepsilon}=0.5 \mathrm{~s}^{-1} \& \varepsilon=0.6$ (b) $\mathrm{T}=370{ }^{\circ} \mathrm{C}, \dot{\varepsilon}=5 \mathrm{~s}^{-1} \& \varepsilon=1.2$ (c) $\mathrm{T}=220{ }^{\circ} \mathrm{C}, \dot{\varepsilon}=0.5 \mathrm{~s}^{-1} \& \varepsilon=0.6$ (d) $\mathrm{T}=220{ }^{\circ} \mathrm{C}, \dot{\varepsilon}=5 \mathrm{~s}^{-1} \& \varepsilon=1.2$.

(Figures 12g and 12h) support the occurrence of dynamic recovery the composite. Lüton and Sellars [37] among other previous authors [62-65] have established that flow stress oscillation is due to dynamic recrystallisation, while elongated grains are well-established indicators of dynamic recovery. From the microstructures presented in this study, it is not clear which mechanism is the dominant restoration mechanism in both composites. However, it is noted that at higher deformation temperature $\left(370{ }^{\circ} \mathrm{C}\right)$, high strain rate $\left(5 \mathrm{~s}^{-1}\right)$ and high strain (1.2), dynamic recrystallisation is favoured especially in the $\mathrm{AA} 6063-\mathrm{Ni}_{\mathrm{p}}$ based composites while dynamic recovery is the prevalent restoration mechanism under other deformation conditions considered in this study. Hence, future work will focus on developing process maps that will delineate the most favourable conditions for either dynamic recovery or dynamic recrystallisation as dominant restoration mechanisms. Also, the parameters (temperature, strain rate and strain) that are potentially unsuitable for deformation of the composites will be established.

\section{Conclusion}

The comparison between the high temperature compression strength, flow behavior and microstructural evolution of $\mathrm{AA} 6063-\mathrm{SiC}_{\mathrm{p}}$ and $\mathrm{AA} 6063-\mathrm{Ni}_{\mathrm{p}}$ composites were evaluated under different deformation temperatures, strain rate and strain. The following conclusions were made:

- The AA6063-Ni $\mathrm{p}_{\mathrm{p}}$ composite exhibited superior compression strength in comparison with $\mathrm{AA} 6063-\mathrm{SiC}_{\mathrm{p}}$ composite irrespective of the testing condition due to the 


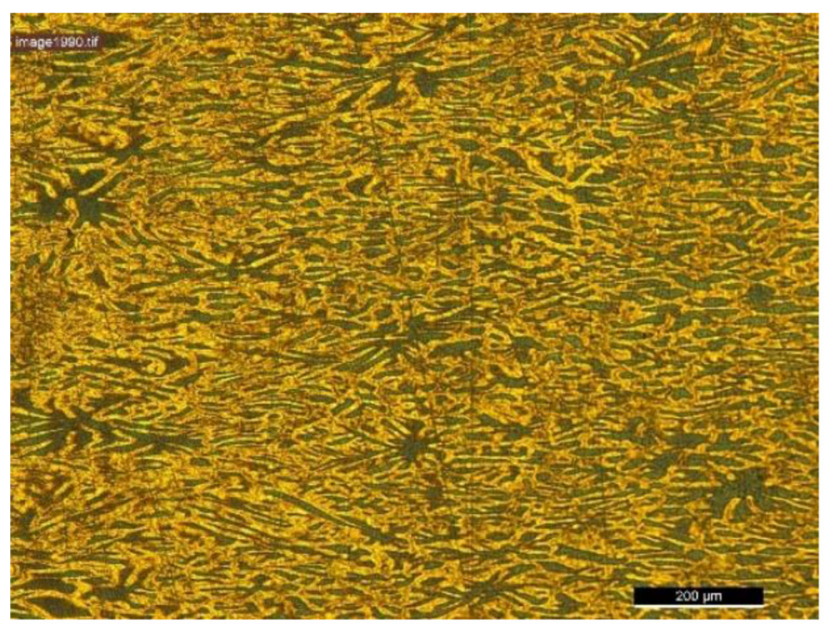

(a)

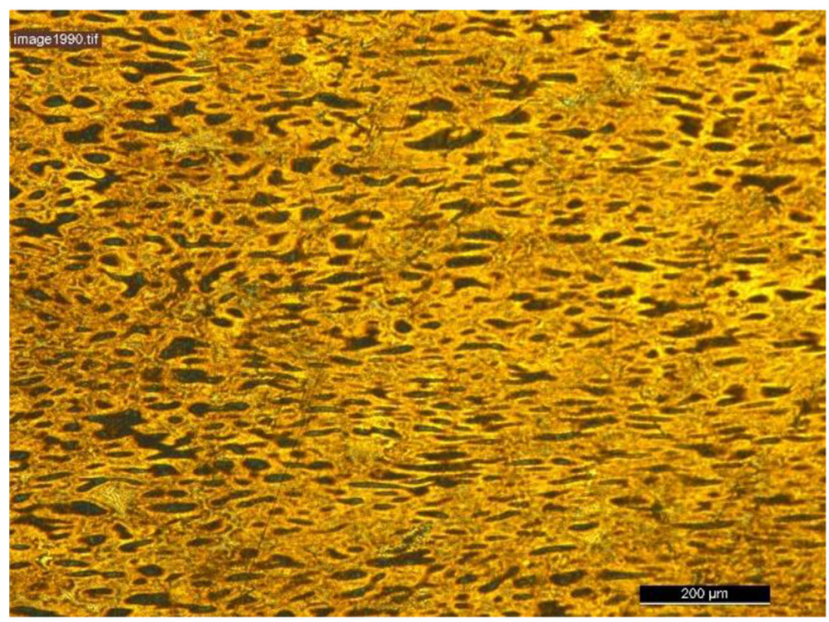

(c)

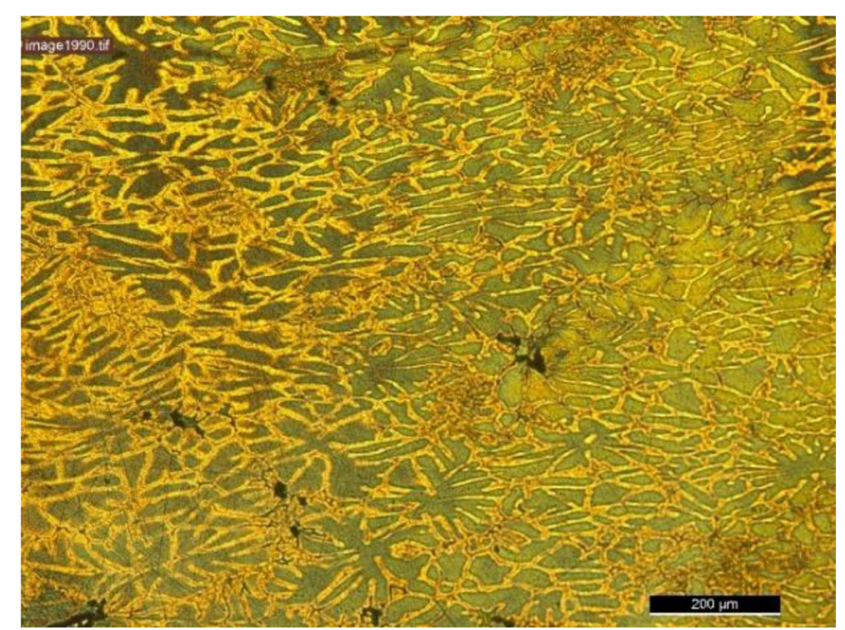

(b)

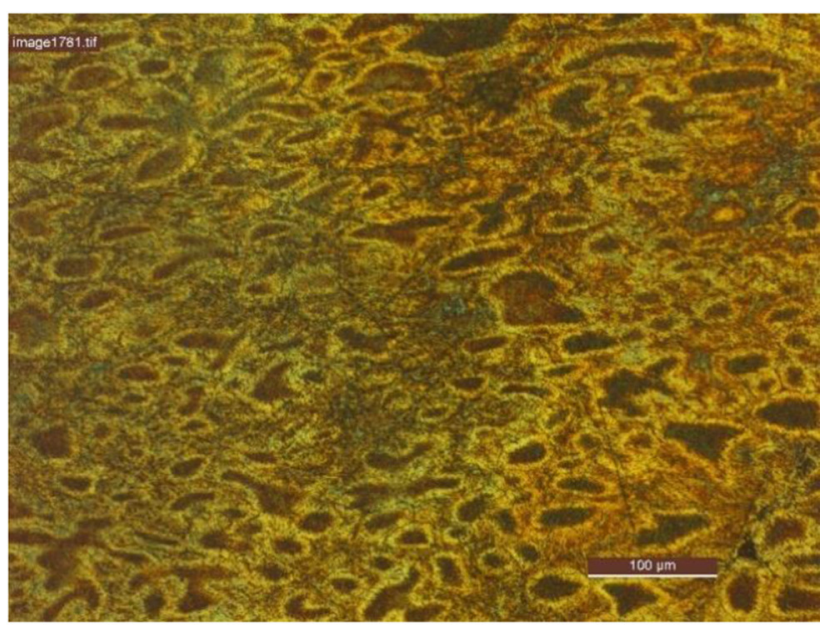

(d)

Fig. 10. Optical images of AA6063-SiC : (a) $\mathrm{T}=220^{\circ} \mathrm{C}, \dot{\varepsilon}=0.5 \mathrm{~s}^{-1} \& \dot{\varepsilon}=0.6$-region $\mathrm{C}$; (b) $\mathrm{T}=220^{\circ} \mathrm{C}, \dot{\varepsilon}=0.5 \mathrm{~s}^{-1} \& \dot{\varepsilon}=0.6-$ region $\mathrm{B}$; and $\mathrm{AA}_{6063 \mathrm{Ni}_{\mathrm{p}}}$ (c) $\mathrm{T}=370^{\circ} \mathrm{C}, \dot{\varepsilon}=0.5 \mathrm{~s}^{-1} \& \dot{\varepsilon}=0.6-$ region $\mathrm{C} ;$ (d) $\mathrm{T}=370^{\circ} \mathrm{C}, \dot{\varepsilon}=0.5 \mathrm{~s}^{-1} \& \dot{\varepsilon}=0.6-$ region $\mathrm{B}$.

presence of distinct network of equiaxed light phase consisting of intermetallic precipitates and nickel particulates at the grain boundaries, and across different regions of the deformed samples. Therefore, the use of metallic reinforcement like nickel in the design of AMCs may be considered as an alternative to conventional ceramic reinforcements for high temperature and high strength applications.

- The AA6063-SiC ${ }_{p}$ composite showed lower resistance to hot deformation in comparison with $\mathrm{AA} 6063-\mathrm{Ni}_{\mathrm{p}}$ composite but the microstructural restoration mechanisms (dynamic recovery and dynamic recrystallisation) controlling the deformation process in both composites are similar. The AA6063- $\mathrm{Ni}_{\mathrm{p}}$ composite tends to be more susceptible to dynamic recrystallisation judging from the higher fraction of equiaxed grains in the composite.

- The variations in the microstructural features across the different deformation regions in both composites showed that deformation was not homogenous under the testing conditions that were considered in this work. Therefore, optimisation of deformation process parameters using processing map approach is recommended in order to obtain homogenous and reproducible microstructure and mechanical properties in the composites. 


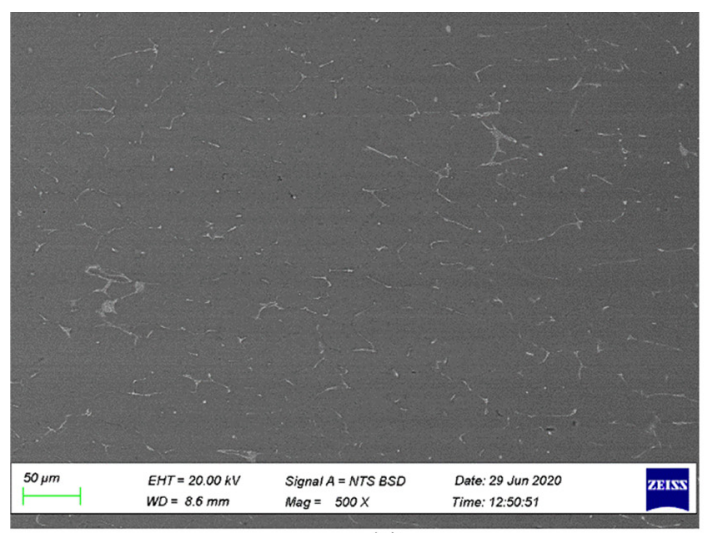

(a)

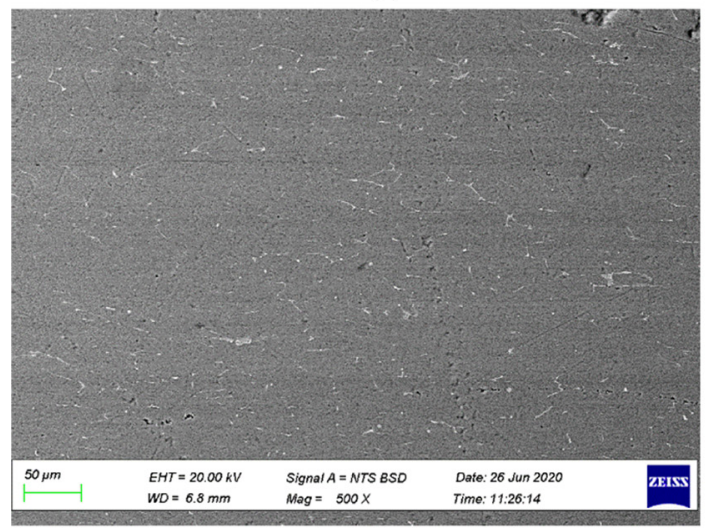

(c)

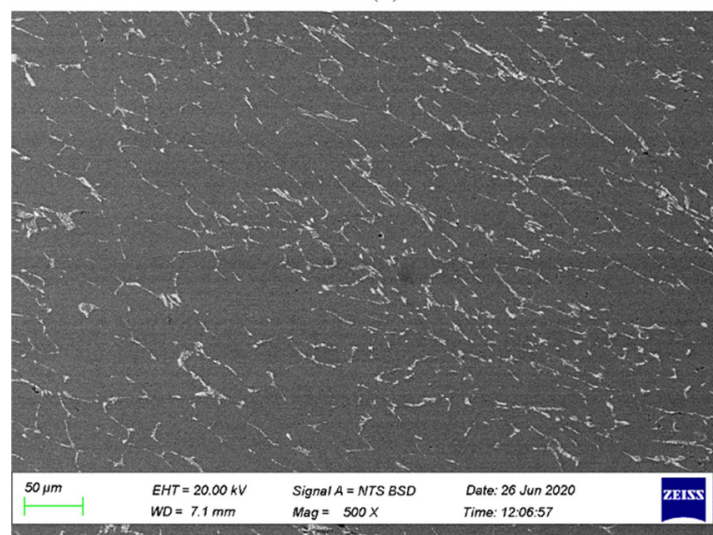

(e)

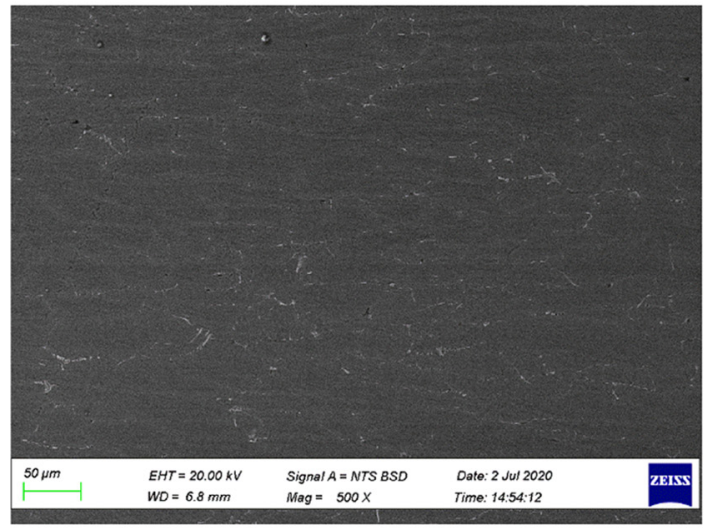

(g)

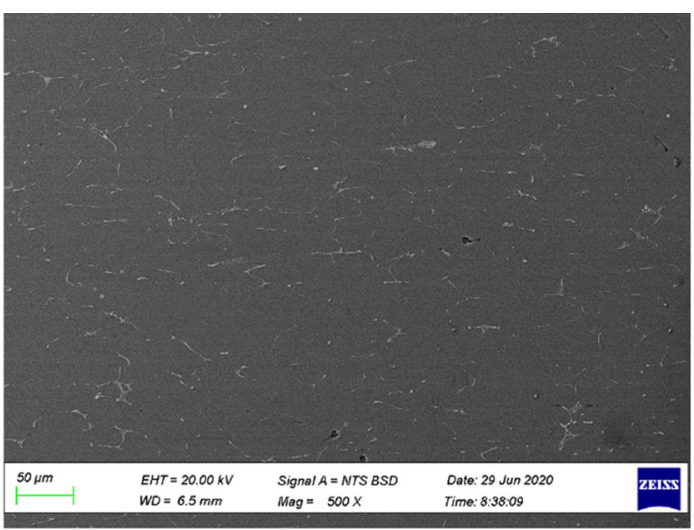

(b)

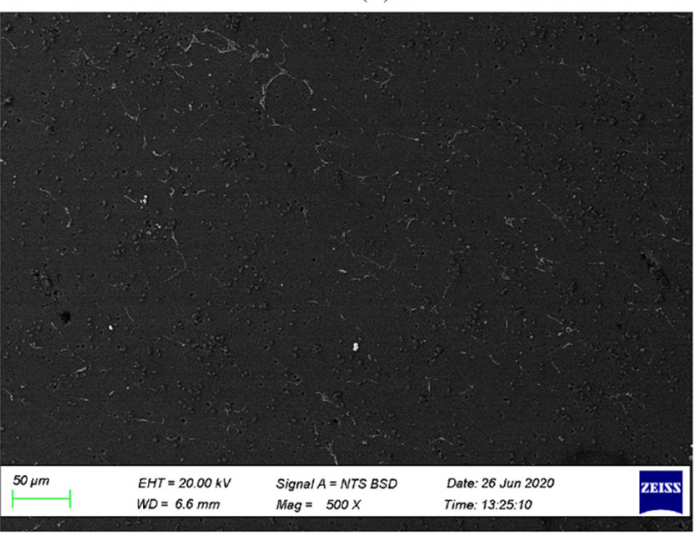

(d)

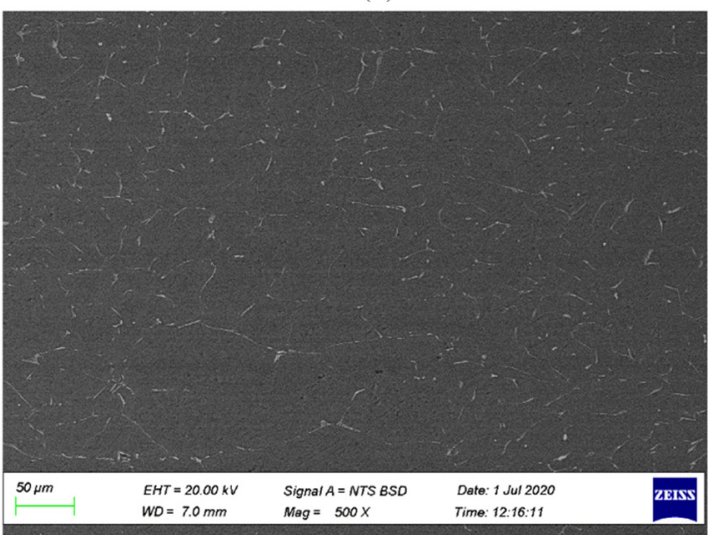

(f)

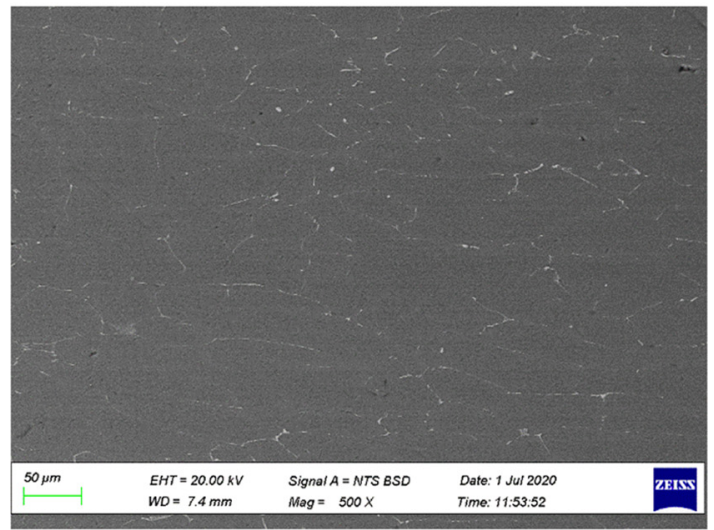

(h)

Fig. 11. SEM-BSE images AA $6063-\mathrm{SiC}_{\mathrm{p}}$ composites taken in region $\mathrm{B}$ of the deformed samples: (a) $\mathrm{T}=370{ }^{\circ} \mathrm{C}, \dot{\varepsilon}=0.5 \mathrm{~s}^{-1} \& \varepsilon=0.6$; (b) $\mathrm{T}=370^{\circ} \mathrm{C}, \dot{\varepsilon}=5 \mathrm{~s}^{-1} \& \varepsilon=0.6$; (c) $\mathrm{T}=370^{\circ} \mathrm{C}, \dot{\varepsilon}=0.5 \mathrm{~s}^{-1} \& \varepsilon=1.2 ;$ (d) $\mathrm{T}=370^{\circ} \mathrm{C}, \dot{\varepsilon}=5 \mathrm{~s}^{-1} \& \varepsilon=1.2 ;(\mathrm{e}) \mathrm{T}=220^{\circ} \mathrm{C}, \dot{\varepsilon}=0.5 \mathrm{~s}^{-1} \&$ $\varepsilon=0.6 ;\left(\right.$ f) $\mathrm{T}=220{ }^{\circ} \mathrm{C}, \dot{\varepsilon}=5 \mathrm{~s}^{-1} \& \varepsilon=0.6(\mathrm{~g}) \mathrm{T}=220^{\circ} \mathrm{C}, \dot{\varepsilon}=0.5 \mathrm{~s}^{-1} \& \varepsilon=1.2$; and (h) $\mathrm{T}=220{ }^{\circ} \mathrm{C}, \dot{\varepsilon}=5 \mathrm{~s}^{-1} \& \varepsilon=1.2$. 


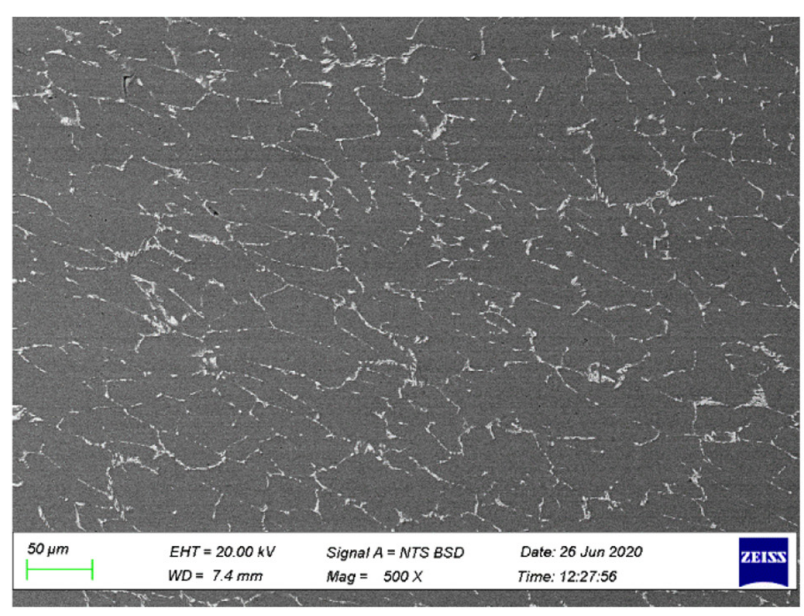

(a)

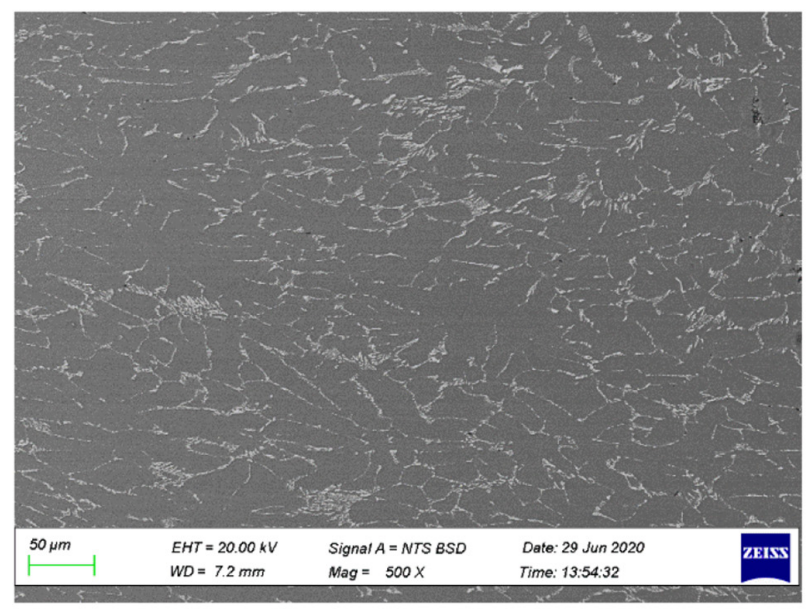

(c)

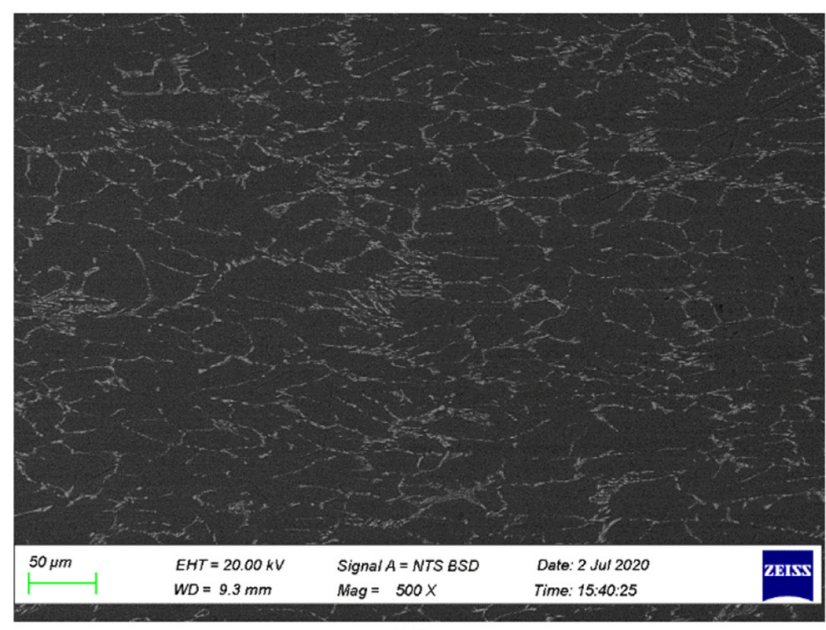

(e)

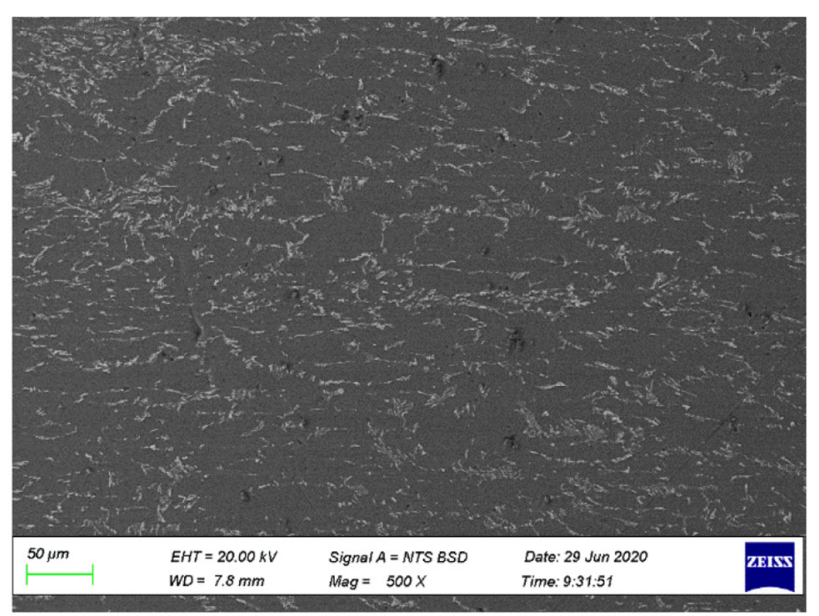

(b)

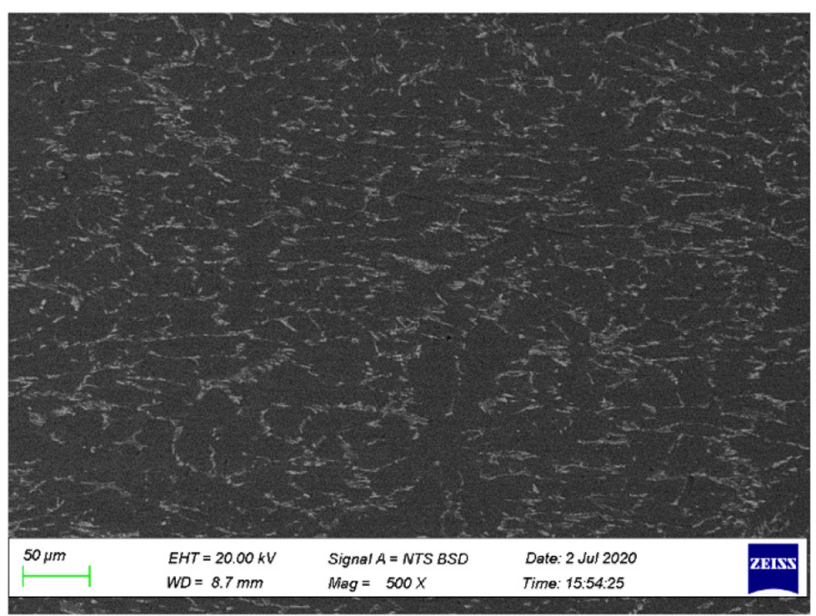

(d)

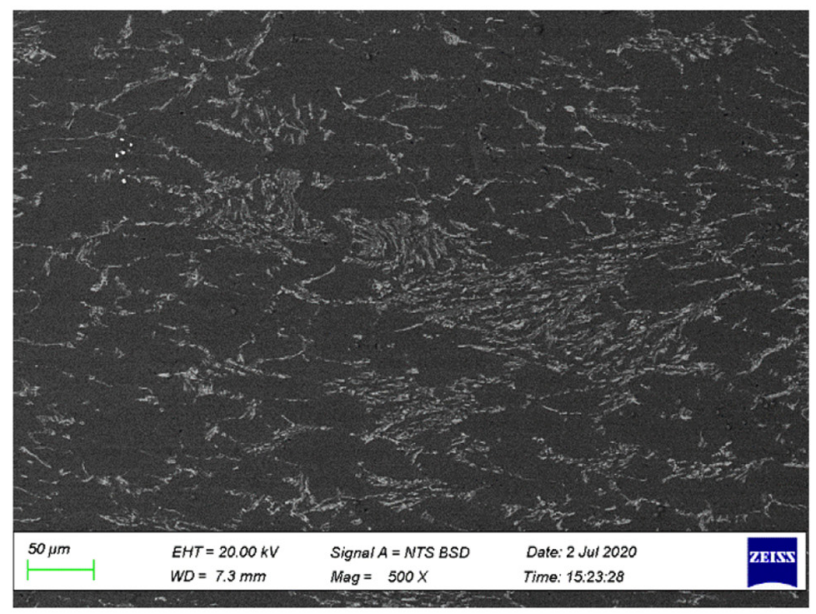

(f)

Fig. 12. SEM-BSE images AA $6063-\mathrm{Ni}_{\mathrm{p}}$ composites taken in region $\mathrm{B}$ of the deformed samples: (a) $\mathrm{T}=370{ }^{\circ} \mathrm{C}, \dot{\varepsilon}=0.5 \mathrm{~s}^{-1} \& \varepsilon=0.6$; (b) $\mathrm{T}=370^{\circ} \mathrm{C}, \dot{\varepsilon}=5 \mathrm{~s}^{-1} \& \varepsilon=1.2 ;(\mathrm{c}) \mathrm{T}=370^{\circ} \mathrm{C}, \dot{\varepsilon}=5 \mathrm{~s}^{-1} \& \varepsilon=1.2 ;(\mathrm{d}) \mathrm{T}=370^{\circ} \mathrm{C}, \dot{\varepsilon}=0.5 \mathrm{~s}^{-1} \& \varepsilon=0.6 ;(\mathrm{e}) \mathrm{T}=220^{\circ} \mathrm{C}, \dot{\varepsilon}=5 \mathrm{~s}^{-1} \&$ $\varepsilon=0.6 ;$ and (f) $\mathrm{T}=220^{\circ} \mathrm{C}, \dot{\varepsilon}=5 \mathrm{~s}^{-1} \& \varepsilon=1.2$. 


\section{References}

1. V. Ferreira, P. Egizabal, V. Popov, M. García de Cortázar, A. Irazustabarrena, A.M. López-Sabirón, G. Ferreira, Lightweight automotive components based on nanodiamond-reinforced aluminium alloy: a technical and environmental evaluation, Diam. Relat. Mater. 92 (2019) $174-186$

2. J. Singh, A. Chauhan, Characterization of hybrid aluminium matrix composites for advanced applications - a review, J. Mater. Res. Technol. 5 (2016) 159-169

3. S.R. Oke, O.E. Falodun, M.R. Mahlatse, O.O. Ige, P.A. Olubambi, Investigation on densification and microstructure of Al-TiO2 composite produced by Spark plasma sintering, Mater. Today Proc. 18 (2019) 3182-3188.

4. M. Shukla, S.K. Dhakad, P. Agarwal, M.K. Pradhan, Characteristic behaviour of aluminium metal matrix composites- a review, Mater. Today Proc. 5 (2018) 5830-5836

5. P. Garg, A. Jamwal, D. Kumara, K.K. Sadasivuni, C.M. Hussain, P.J. Gupta, Advance research progresses in aluminium matrix composites: manufacturing and applications, Mater. Res. Technol. 8 (2019) 4924-4939

6. X. Liu, J. Li, E. Liu, C. He, C. Shi, N. Zhao, Towards strength-ductility synergy with favorable strengthening effect through the formation of a quasi-continuous graphene nanosheets coated $\mathrm{Ni}$ structure in aluminum matrix composite, Mater. Sci. Eng. A 748 (2019) 52-58

7. R.T. Mousavian, S. Behnamfard, R.A. Khosroshahi, J. Zavašniksssss, P. Ghosh, S. Krishnamurthy, A. Heidarzadeh, D. Brabazon, Strength-ductility trade-off via $\mathrm{SiC}$ nanoparticle dispersion in A356 aluminium matrix, Mater. Sci. Eng. A 170 (2019) 586-592

8. K.K. Alaneme, Y.O. Anabaranze, S.R. Oke, Softening resistance, dimensional stability and corrosion behaviour of alumina and rice husk ash reinforced aluminium matrix composites subjected to thermal cycling, Tribol. Ind. 37 (2015) 204-214.

9. S.P. Shivakumar, A.S. Sharan, K. Sadashivappa, Experimental investigations on vibration properties of aluminium matrix composites reinforced with iron oxide particles, Appl. Mech. Mater. 895 (2019) 22-126

10. G. Garces, P. Pérez, R. Barea, J. Medina, A. Stark, N. Schell, $\mathrm{P}$. Adeva, Increase in the mechanical strength of Mg-8Gd$3 \mathrm{Y}-1 \mathrm{Zn}$ alloy containing long-period stacking ordered phases using equal channel angular pressing processing, Metals 221 (2019) 1-17

11. Q.L. Zhao, T.T. Shan, R. Geng, Y.Y. Zhang, H.Y. He, F. Qiu, Q.C. Jiang, Effect of preheating temperature on the microstructure and tensile properties of 6061 aluminum alloy processed by hot rolling-quenching, Metals 182 (2019) $1-8$

12. T. Ye, Y. Xu, J. Ren, Effects of $\mathrm{SiC}$ particle size on mechanical properties of SiC particle reinforced aluminum metal matrix composite, Mater. Sci. Eng. A 753 (2019) $146-155$

13. K.C. Nayak, P.P. Date, Hot deformation flow behavior of powder metallurgy based $\mathrm{Al}-\mathrm{SiC}$ and $\mathrm{Al}-\mathrm{Al}_{2} \mathrm{O}_{3}$ composite in a single step and two-step uni-axial compression, Mater. Charact. 151 (2019) 563-581
14. V. Bharath, S.S. Ajawan, M. Nagaral, V. Auradi, S.A. Kori, Characterization and mechanical properties of2014 aluminum Alloy reinforced with $\mathrm{Al}_{2} \mathrm{O}_{3}$ composite produced by twostage stir casting route, J. Inst. Eng. India Ser. C 100 (2019) $277-282$

15. J. Liu, Z. Chen, F. Zhang, G. Ji, M. Wang, Y. Ma, V. Ji, S. Zhong, Y. Wu, H. Wang, Simultaneously increasing strength and ductility of nanoparticles reinforced $\mathrm{Al}$ composites via accumulative orthogonal extrusion process, Mater. Res. Lett. 6 (2018) 406-412

16. J. Hashim, L. Looney, M.S.J. Hashmi, The enhancement of wettability of $\mathrm{SiC}$ particles in cast aluminium matrix composites, J. Mater. Process. Technol. 119 (2001) 329-335

17. G. Li, Y. Qu, Y. Yang, Q. Zhou, X. Liu, R. Li, Improved multi-orientation dispersion of short carbon fibers in aluminum matrix composites prepared with square crucible by mechanical stirring, J. Mater. Sci. Tech. 40 (2020) 81-87

18. A. Tan, J. Teng, X. Zeng, D. Fu, H. Zhang, Fabrication of aluminium matrix hybrid composites reinforced with $\mathrm{SiC}$ microparticles and $\mathrm{TiB}_{2}$ nanoparticles by powder metallurgy, Powder Metall. 60 (2017) 66-72

19. S. Sharma, T. Nanda, O.P. Pandey, Effect of particle size on dry sliding wear behaviour of sillimanite reinforced aluminium matrix composites, Ceram. Int. 44 (2018) 104-114

20. K. Shirvanimoghaddam, H. Khayyam, H. Abdizadeh, M.K. Akbari, A.H. Pakseresht, F. Abdi, A. Abbasi, M. Naebe, Effect of $\mathrm{B}_{4} \mathrm{C}, \mathrm{TiB}_{2}$ and $\mathrm{ZrSiO}_{4}$ ceramic particles on mechanical properties of aluminium matrix composites: experimental investigation and predictive modelling, Ceram. Int. 42 (2016) 6206-6220

21. K.J. Joshua, S.J. Vijay, D.P. Selvaraj, Effect of nano $\mathrm{TiO}_{2}$ particles on microhardness and microstructural behaviour of AA7068 metal matrix composites, Ceramics 44 (2018) 20774-20781

22. J. Gayathri, R. Elansezhian, Influence of dual reinforcement (nano $\mathrm{CuO}+$ reused spent alumina catalyst) on microstructure and mechanical properties of aluminium metal matrix composite, J. Alloys Compd. 829 (2020) 154538

23. A. Tan, J. Teng, X. Zeng, D. Fu, H. Zhang, Fabrication of aluminium matrix hybrid composites reinforced with $\mathrm{SiC}$ microparticles and $\mathrm{TiB}_{2}$ nanoparticles by powder metallurgy, Powder Metall. 60 (2017) 66-72

24. F.E. El-Labban, M. Abdelaziz, E.R.I. Mahmoud, Preparation and characterization of squeeze cast Al-Si piston alloy reinforced by $\mathrm{Ni}$ and nano $\mathrm{Al}_{2} \mathrm{O} 3$ particle, J. King Saud Univ. Eng. Sci. 28 (2016) 230-239

25. J. Li, J. Nie, Q. Xu, K. Zhao, X. Liu, Enhanced mechanical properties of a novel heat resistant Al-based composite reinforced by the combination of nano-aluminides and submicron TiN particles, Mater. Sci. Eng. A 770 (2020) 138488

26. S. Aktaş, E. Diler, A review on the effects of micro-nano particle size and volume fraction on microstructure and mechanical properties of metal matrix composites manufactured via mechanical alloying, Int. Adv. Res. Eng. 2 (2018) $74-68$

27. R.J.H. Navasingh, R. Kumar, K. Marimuthu, S. Planichamy, A. Khan, A.M. Asiri, M. Asad, A review. Chap. 6. In nanocarbon and its composites: Preparation, properties and applications Sawston, UK: Woodhead Publishing Series, Compos. Eng. 6 (2019) 153-170 
28. M.O. Bodunrin, K.K. Alaneme, L.H. Chow, Aluminium matrix hybrid composites: A review of reinforcement philosophies; mechanical corrosion and tribological characteristics, J. Mater. Res. Technol. 4 (2015) 434-445

29. K.K. Alaneme, E.A. Okotete, V.A. Fajemisin, M.O. Bodunrin, Applicability of metallic reinforcements for mechanical performance enhancement in metal matrix composites: a review, J. Arab. Basic Appl. Sci. 26 (2019) 311-330

30. G. Krishna, K.P. Kumar, M.N. Swapna, B.J. Rao, N.R.M.R. Bhargava, Fabrication characterization and mechanical behaviour of A356/copper particulate reinforced metallic composites, Mater. Today Proc. 5 (2018) 7685-7691

31. S. Madhusudan, M.M.M. Sarcar, N.B.R.M. Rao, Mechanical properties of Aluminum-Copper $(\mathrm{p})$ composite metallic materials, J. Appl. Res. Technol. 14 (2016) 293-299

32. A. Szlancsik, B. Katona, K. Bobor, K. Májlinger, I.N. Orbulov, Compressive behaviour of aluminium matrix syntactic foams reinforced by iron hollow spheres, Mater. Des. 83 (2015) 230-237

33. K.K. Alaneme, A.O. Aluko, Production and age hardening behaviour of borax premixed silicon carbide reinforced $\mathrm{Al}-\mathrm{Mg}$-Si alloy composites developed by double stir casting techniques, West Indian J. Eng. 34 (2012) 80-85

34. K.K. Alaneme, S.A. Babalola, M.O. Bodunrin, On the prediction of hot deformation mechanisms and workability in Al6063/Nip and Al6063/steelp composites using hyperbolic-sine constitutive equation, Mater. Today Proc. (2020). https://doi.org/10.1016/j.matpr.2020.05.463

35. Gleeble Application Note APN 017 https://www.gleeble. com/resources/application-notes.html

36. S. Solhjoo, S. Khoddam, Evaluation of barrelling and friction in uniaxial compression test: a kinematic analysis, Int. J. Mech. Sci. 15 (2019) 486-493

37. M.J. L $\ddot{\bar{u}}$ ton, C.M. Sellars, Dynamic recrystallization in nickel and nickel-iron alloys during high temperature deformation, Acta Metall. 17 (1969) 1033-1043

38. K. Wang, X. Li, G. Shu, G. Tang, Hot deformation behavior and microstructural evolution of particulate reinforced AA6061/ $\mathrm{B}_{4} \mathrm{C}$ composite during compression at elevated temperature, J. Mater. Sci. Eng. A 696 (2017) 248-256

39. Y.Y. Zong, D.B. Shan, M. Xu, Y. Lv, Flow softening and microstructural evolution of TC11 titanium alloy during hot deformation, J. Mater. Process. Technol. 209 (2009) 1988-1994

40. R.D. Doherty, D.A. Hughes, F.J. Humphreys, J.J. Jonas, D.J. Jensen, M.E. Kassner, W.E. King, T.R. McNelley, H.J. McQueen, A.D. Rollett, Current issues in recrystallization: a review, Mater. Sci. Eng. A 238 (1997) 219-274

41. W. Chuan, H. Liang, Hot deformation and dynamic recrystallization of a near-beta titanium alloy in the $\beta$ single phase region, Vacuum 156 (2018) 384-401

42. H. Mirzadeh, Constitutive modelling and prediction of hot deformation flow stress under dynamic recrystallization conditions, Mech. Mater. 85 (2015) 66-79

43. M. Härtel, C. Illgen, P. Frint, M. Wagner, On the PLC effect in a particle reinforced AA2017 alloy, Metals 8 (2018) 88-95

44. L. Blaz, P. Lobry, M. Zygmunt-Kiper, J. Koziel, G. Wloch, S. Dymek, Strain rate sensitivity of Al-based composites reinforced with $\mathrm{MnO}_{2}$ additions, J. Alloys Compd. 619 (2015) 652-658
45. X. Feng, G. Fischer, R. Zielke, J. Svendsen, W. Tillmann, Investigation of PLC band nucleation in AA5754, Mater. Sci. Eng. A 539 (2012) 205-210

46. Y.P. Li, E. Onodera, H. Matsumoto, A. Chiba, Correcting the stress-strain curve in hot compression process to high strain level, Metall. Mater. Trans. A 40 (2009) 982-990

47. J.M. Mistry, P.P. Gohil, Research review of diversified reinforcement on aluminum metal matrix composites: fabrication processes and mechanical characterization, Sci. Eng. Compos. Mater. 25 (2018) 633-647

48. B.V. Ramnath, C. Elanchezhian, R.M. Annamalai, S. Aravind, T.S.A. Atreya, V. Vignesh, C. Subramanian, Aluminium metal matrix composites - a review, Rev. Adv. Mater. Sci. 38 (2014) 55-60

49. D. Yadav, R. Bauri, Nickel particle embedded aluminium matrix composite with high ductility. Mater. Lett. 64 (2010) 664-667

50. Y.V.R.K. Prasad, K.P. Rao, S. Sasidhara, Hot working guide: a compendium of processing maps, ASM Int. (2015) 1-438

51. H.J. McQueen, D.L. Bourell, Hot workability of metals and alloys, J. Mater. 39 (2012) 28-35

52. H. Shi, A. Mclaren, A. Sellars, C.M.R. Shahani, R. Bolingbroke, Constitutive equations for high temperature flow stress of aluminium alloys, Mater. Sci. Technol. 13 (1997) 210-216

53. F. Warchomicka, C. Poletti, M. Stockinger, H.P. Degischer, Determination of the mechanism of restoration in subtransus hot deformation of Ti-6Al-4V, Mater. Sci. Forum, 706-709 (2012) 252-257

54. C. Poletti, L. Germain, F. Warchomicka, M. Dikovits, S. Mitsche, Unified description of the softening behavior of beta-metastable and alpha+beta titanium alloys during hot deformation, Mater. Sci. Eng. A 651 (2016) 280-290

55. C. Poletti, H. Dieringa, F. Warchomicka, Local deformation and processing maps of as-cast AZ31 alloy, Maters. Sci. Eng. A 516 (2009) 138-147

56. J. Asensio-Lozano, B. Suárez-Peña, G.F. Vander Voort, Effect of processing steps on the mechanical properties and surface appearance of 6063 aluminium extruded products, Materials 7 (2014) 4224-4242

57. B. Leszczynska-Madej, M. Richert, A. Wasik, A. Szafron, Analysis of the microstructure and selected properties of the aluminium alloys used in automotive air-conditioning systems, Metals 8 (2018) 1-15

58. G. Vander Voort, B. Suárez-Peña, J. Asensio-Lozano, Microstructure investigations of streak formation in 6063 aluminum extrusions by optical metallographic techniques, Microsc. Microstruct. Anal. 19 (2013) 276-284

59. D. Yadav, R. Bauri, Nickel particle embedded aluminium matrix composite with high ductility, Mater. Lett. 64 (2010) 664-667

60. Y.V.R.K. Prasad, T. Seshacharyulu, Modelling of hot deformation for microstructural control, Int. Mater. Rev. 43 (1998) 243-258

61. T. Seshacharyulu, S.C. Medeiros, W.G. Frazier, Y.V.R.K. Prasad, Microstructural mechanisms during hot working of commercial grade $\mathrm{Ti}-6 \mathrm{Al}-4 \mathrm{~V}$ with lamellar starting structure, Mater. Sci Eng. A 325 (2002) 112-125 
62. E. Evangelista, H.J. Mcqueen, N.D. Ryan, Hot strength, dynamic recovery and dynamic recrystallization of 317 type stainless steel, Metall. Sci. Technol. 5 (1987) $50-58$

63. P. Wanjara, M. Jahazi, H. Monajati, S. Yue, J.P. Immarigeon, Hot working behavior of near- $\alpha$ alloy IMI834, Mater. Sci. Eng. A 396 (2005) 50-60
64. Y. Duan, P. Li, K. Xue, Q. Zhang, X. Wang, Flow behaviour and microstructure evolution of TB8 alloy during hot deformation process, Trans. Nonferrous Met. Soc. China 17 (2007) 1199-1204

65. J.K. Fan, H.C. Kou, M.J. Lai, B. Tang, H. Chang, J.S. Li, Hot deformation mechanism and microstructure evolution of a new near $\beta$ titanium alloy, Mater. Sci. Eng. A 584 (2013) 121-132

Cite this article as: Saheed Adeoye Babalola, Kenneth Kanayo Alaneme, Samuel Ranti Oke, Lesley Heath Chown, Nthabiseng Beauty Maledi, Michael Oluwatosin Bodunrin, Hot compression behaviour and microstructural evolution in aluminium based composites: an assessment of the role of reinforcements and deformation parameters, Manufacturing Rev. 8, 6 (2021) 